\title{
Microfluidics featuring multilayered hydrogel assemblies enable real-time NMR-monitoring of enzyme cascade reactions
}

\author{
Nurdiana Nordin ${ }^{\S 1,2}$, Lorenzo Bordonali ${ }^{\S}{ }^{1}$, Hossein Davoodi ${ }^{1}$, Novindi Dwi Ratnawati ${ }^{1}$, Gudrun \\ Gygli $^{3}$, Jan G. Korvink ${ }^{1}$, Vlad Badilita ${ }^{* 1}$, and Neil MacKinnon*1 \\ ${ }^{1}$ Institute of Microstructure Technology, Karlsruhe Institute of Technology, Eggenstein-Leopoldshafen, Germany \\ ${ }^{2}$ Department of Chemistry, Faculty of Science, University of Malaya, Kuala Lumpur, Malaysia \\ ${ }^{3}$ Institute of Biological Interfaces, Karlsruhe Institute of Technology, Eggenstein-Leopoldshafen, Germany
}

\begin{abstract}
Compartmentalized chemical reactions at the microscale are interesting from many perspectives including (multi)functional surfaces and biotechnology. Monitoring the molecular content as a measure of functional performance at these small scales is challenging. As a means to address this challenge, we leverage microtechnology and biocompatible materials to integrate a compact, reconfigurable reaction cell featuring electrochemical functionality with high-resolution nuclear magnetic resonance spectroscopy (NMR). We demonstrate the operation of this system by monitoring the activity of enzymes immobilized in chemically distinct layers within a multi-layered chitosan hydrogel assembly. As a benchmark, we observed the parallel activities of urease (Urs), catalase (Cat), and glucose oxidase (GOx) by recording NMR spectra to extract reagent and product concentrations in real-time. As a result, simultaneous monitoring of a cooperative enzymatic process $(\mathrm{GOx}+\mathrm{Cat})$ together with an independent process (Urs) is achieved. Using Michaelis-Menten progress curve analysis of the NMR data, kinetic data is extracted: in the case of GOx, the Michaelis constants $\left(K_{M}\right)$ are consistent with previous reports, while for Urs, deviations are observed, attributed to an inhibitory effect under our reaction conditions. The system therefore enables the construction of complex reaction cascades with spatial control, as would be interesting in, for example, metabolic engineering and multiplexed sensing applications.
\end{abstract}

\section{Introduction}

Reproducing metabolic reactions in a controlled space that mimics the native micro-environmental conditions inside biological matter is an endeavour that can have important repercussions on bio-medical applications ${ }^{[1]}$. Spatial and temporal control over the processes that regulate metabolic activity allows to fine-tune the dynamics underlying the metabolic reaction cascade, thereby enabling researchers to engineer i) models that imitate biological environments at various spatial scales (i.e. extraand intracellular spaces) and ii) metabolic systems with

\footnotetext{
${ }^{0 \S}$ These authors contributed equally to this work.

0*Corresponding authors: VB (vlad.badilita@kit.edu), NM (neil.mackinnon@kit.edu)
}

an optimized spatial arrangement of specific catalysts for a targeted application (e.g. bio-waste management, bioproduction). From a medical perspective, several diagnostic platforms have been developed to inspect biomolecular abundance of metabolites with high sensitivity ${ }^{[2]}$, allowing early detection of diseases ${ }^{[3]}$ and providing valuable insights into system-level ${ }^{[4]}$ chemistry.

Highly hydrated polymer networks (hydrogels) are commonly used to mimic and interface with biological spaces, and their sophistication continues to evolve to keep pace with the desired performance in drug delivery, tissue engineering, and biosensing applications. ${ }^{[5-8]}$ There are numerous possibilities to generate hydrogels and their composites, and one attractive route to achieve localized hydrogels in both space and time is to uti- 
lize the stimuli-responsive hydrogel sub-class. In this class, the sol-gel transition can be controlled and triggered by applying an appropriate signal; in some cases, the sol-gel transition is reversible making the system attractive, for example, in biosensing applications where the hydrogel is resettable dependent on the sensing demands. Electrochemical-based fabrication of chitosan hydrogels is one system exploited for hydrogel assembly with high spatio-temporal precision. ${ }^{[9,10]}$ Chitosan is an attractive material given its biocompatibility, reversible gelation, and amenability to chemical functionalization properties. ${ }^{[11-14]}$ In addition, electrodeposition is relatively uncomplicated, requiring a two electrode system in contact with a chitosan solution to generate a local increase in $\mathrm{pH}$ with an applied current, thereby causing local deposition of the chitosan hydrogel. This has been exploited for (bio)sensing ${ }^{[15-18]}$ and controlled release ${ }^{[19,20]}$ applications.

Since the deposition process is controlled by an electrical signal, the architecture of the hydrogel can be varied simply by modulating the trigger signal. This results in a multilayered structure, ${ }^{[21,22]}$ which can be used to encode information $^{[23]}$ or to generate cell bioreactors. ${ }^{[24]}$ Taking advantage of the ability to chemically functionalize chitosan prior to deposition, each layer can be additionally assigned a unique chemical identity. ${ }^{[25]}$ In this way, complex hydrogel structures can be assembled with programmable spatial separation of chemical function. Given that control of layer thickness can be on the order of micrometers, there is potential to leverage this technology in the direction of replicating the spatial localization of metabolic and functional elements within tissues. At these length scales, microfluidic methods are critical for the handling and management of the resultant small sample volumes.

Nuclear magnetic resonance (NMR) spectroscopy in combination with microfluidics has been identified as a powerful analytical method when both small sample management and in situ investigation of metabolic activity are required. ${ }^{[26-28]}$ NMR is non-invasive and reports on the dynamics of a (bio)chemical reaction with high resolution along both time and frequency (i.e. chemical) dimensions. In the context of NMR monitoring of localized metabolic activity, the challenge is to integrate additional functionalities into the detection space without degrading the SNR of the NMR signal and without perturbing the homogeneity of the local magnetic environment necessary for high quality NMR spectra. It was previously reported that integration of hardware elements for simple electrochemical manipulations inside the active region of an NMR micro-detector is possible, without compromising the overall quality of the recorded spectrum ${ }^{[29]}$.

In this report, we describe functional monitoring of spatially localized enzymes within a microfluidic device by a micro-NMR system. By electrodeposition, a chitosan hydrogel was co-localized with an electrode while the catalytic potential perpendicular to the electrode surface was controlled by sequential deposition of chitosan layers modified with different enzymes. Urease (Urs), glucose oxidase (GOx), and catalase (Cat) were selected for a three-layer system, representing independent conversion of urea (to ammonia via Urs) and glucose (to gluconic acid via GOx) and a coupled enzymatic reaction (peroxide generated by GOx to water via Cat). In the microfluidic device, conversion of approximately $3 \mu \mathrm{mol}$ of urea and $0.3 \mu \mathrm{mol}$ of glucose by a multi-functional chitosan hydrogel was measured, demonstrating simultaneous monitoring of multiple biocatalytic reactions within a hydrogel matrix.

\section{Results and Discussion}

\section{Platform configuration}

A custom NMR probe head insert, compatible with a commercial Bruker Micro5 microimaging NMR probe, was designed and fabricated to enable NMR monitoring of an in situ electrodeposition experiment (Figure 1). The NMR detector used in this work is a Helmholtz pair with a $1.2 \mathrm{~mm}$ diameter and $600 \mu \mathrm{m}$ separation between the two windings. ${ }^{[27]}$ The microcoil was mounted on top of a PCB, hosting both the ${ }^{1} \mathrm{H}$ NMR channel tracks path, interfaced to the NMR probe head, and chitosan electrodeposition tracks, connected to a power source outside of the magnet using a PCB pin-header (Figure 1a). The support structure of the probe insert was fabricated in PMMA.

Two variations of an application-specific sample insert ${ }^{[27]}$ were considered for the in situ electrochemistry experiment. For the first variation, the electrode pair was planar and was patterned on the bottom surface of the microfluidic channel (planar configuration): one round 
working electrode with a $1.5 \mathrm{~mm}$ diameter (total area $1.76 \mathrm{~mm}^{2}$ ) and a rectangular counter electrode $1.5 \mathrm{~mm} \times$ $2 \mathrm{~mm}$. In this case the microfluidic channel had a total sample capacity of $3.2 \mu \mathrm{L}$.

For the second variation, the electrodes were placed along the walls of a $1.1 \mathrm{~mm}$-wide fluidic channel (sidewall configuration) so that, when inserted into the NMR detector, the electrodes were at the periphery of the Helmholtz coil. In this configuration, the area of both the working and the counter electrodes is $0.43 \mathrm{~mm}^{2}$ and the total sample capacity is $2.6 \mu \mathrm{L}$. Details regarding the design and fabrication of the electrodeposition sample inserts, as well as a discussion about the compatibility with the Helmholtz NMR detector, have been reported elsewhere. ${ }^{[29]}$

Electrical connection to the host PCB electrodeposition lines was done by soldering tin-plated copper wire to the gold pads of the microfluidic insert (Figure 1c). Fluidic contact with the insert was achieved by interfacing soft silicon tubing to the glass insert inlet and outlet ports using custom connectors (machined Teflon) and soft PDMS pads (Figure 1b). The silicon tubing was fed to the top of the insert assembly and connected to fluidic lines outside of the magnet bore.

After assembly and installation of the probe, a typical NMR experiment proceeded as follows (Figure 1c): 1) a solution containing chitosan functionalized with the desired enzyme was flushed through the system to fill the microfluidic insert; 2) a DC current was applied to the pair of electrodes for $15 \mathrm{~min}$ to perform hydrogel electrodeposition; 3) a rinsing solution (buffered at $\mathrm{pH} 7$ ) was gently flushed through to stabilize the hydrogel; 4) a solution containing the desired substrates was flushed through the system. Depending on the particular experiment, steps 1 3 were repeated to build a layered hydrogel before flushing the gel stack with substrate solution. After step 4) the probe was inserted into the magnet bore to begin the NMR measurement routine.

NMR spectra were collected on a Bruker AVANCE system operating at a ${ }^{1} \mathrm{H}$ Larmor frequency of $500.13 \mathrm{MHz}$. A series of spectra were collected, each acquisition requiring 9 min with a 15 min delay between subsequent acquisitions, so that initiation of acquisitions were separated by $24 \mathrm{~min}$ in time. The microfluidic insert placement was such that the working electrode in the planar configuration was not within the NMR detector (i.e. the hydrogel

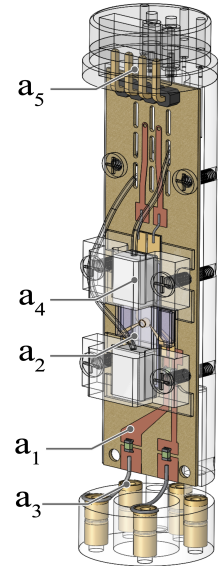

a)

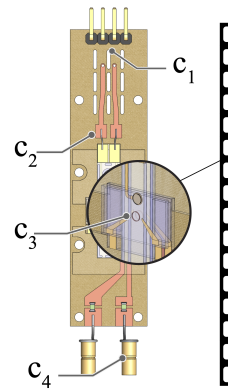

c)

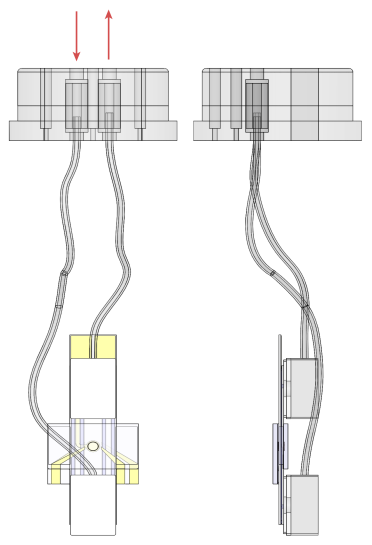

b)

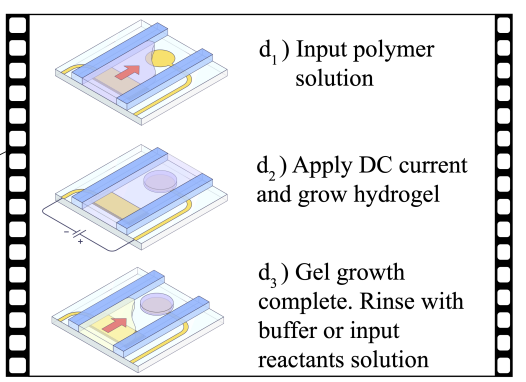

d)
Figure 1: Experimental setup for in situ electrodeposition of pre- and post- modified chitosan inside the microfluidic chip. a) overview of the NMR probe head insert used in this work, showing the main elements of the device: a1) PCB hosting RF tracks, tuning and matching fixed capacitors, the electrodeposition tracks and the NMR microcoil, a2) the microfluidic insert mounted inside the Helmholtz pair microcoil, a3) insert base with RF female connectors, a4) microfluidic connectors and connectors clamps, a5) topside connector supporting both electrical and fluidic connections to the outside. b) schematic of fluidic components, left side view and top view. c) highlighted electrical components: c1) electrodeposition lines and PCB header connector, c2) tin-plated copper connections between PCB and microfluidic insert, c3) microcoil NMR detector, c4) ${ }^{1} \mathrm{H}$ NMR RF lines. d) schematic illustration of the in situ electrodeposition process: d1) loading the microfluidic channel with the polymer solution, d2) applying a DC bias to the electrode pair to initiate elec3 trodeposition, $\mathrm{d} 3$ ) rinsing with a buffer and/or loading the channel with a reagent solution. 
was not in the detector), while the electrodes were placed at the periphery of the detector in the side-wall configuration (i.e. the hydrogel was in the detector).

\section{Preparation of enzymes bound to CSPEG}

In this work, urease (Urs: jack bean, EC 3.5.1.5), catalase (Cat: bovine liver, EC 1.11.1.6), and glucose oxidase (GOx: from Aspergillus niger, EC 1.1.3.4) were chosen as model enzymes to verify that i) covalent enzyme attachment to chitosan does not inhibit their catalytic ability; ii) catalytic activity is maintained when deposited as a multilayered hydrogel; iii) microfluidic NMR can be used to monitor catalytic turnover. Both Urs and GOx have been observed to be catalytically active while integrated within a hydrogel. ${ }^{[30]}$

The enzymes were connected to chitosan using a di-functional polyethylene glycol (PEG) linker and NHS/EDC coupling chemistry. It was observed previously that PEG retains molecular mobility when tethered to chitosan, ${ }^{[29]}$ and therefore it was anticipated this mobility would be useful in maintaining enzyme function. Coupling efficiency to the PEG-modified chitosan was estimated by UV/Vis spectroscopic analysis of the reaction solution after precipitation of the hydrogel (Figure S2). The coupling efficiencies observed were $41 \%$ for Urs and $35 \%$ for GOx (Table 1). This value is important when determining the number of active units of enzyme as describe below.

\section{Monitoring enzyme activity}

The number of active enzyme units extracted from the initial slopes of the kinetic data was used to determine the catalytic performance under various conditions. These conditions included enzyme in solution, enzyme-coupled polymer in solution, and enzyme-coupled polymer in the hydrogel state.

(1) Enzymes in solution, pre- and post-coupling. The number of active units was used as a metric to investigate the influence of the coupling chemistry and hydrogel immobilization on enzyme performance. Urs was tested by transferring a solution containing $2 \mathrm{mg} \mathrm{mL}^{-1}$ Urs + $1000 \mathrm{mM}$ urea to the microfluidic channel $(3.2 \mu \mathrm{L})$ for NMR measurement ( $\mathrm{pH} 5.5, \mathrm{NaAc})$. The resulting NMR data are plotted in Figure 2a (pink). As per the manufacturer data sheet, $0.633 \pm 0.006 \mathrm{U}$ of Urs were expected using $2 \mathrm{mg} \mathrm{mL}^{-1}$ Urs, while the measurement revealed $0.057 \pm 0.013 \mathrm{U}$ of Urs, i.e. the active fraction was $9 \pm 2 \%$.

The procedure was repeated using CS-Urs in $1000 \mathrm{mM}$ urea solution ( $\mathrm{pH} 5.5, \mathrm{NaAc})$. The results are presented in Figure 2a (pink). The CS-Urs solution was prepared so that the concentration of Urs was $2 \mathrm{mg} \mathrm{mL}^{-1}$ and, accounting for the coupling yield, $0.259 \pm 0.007 \mathrm{U}$ of Urs was expected. The measurement revealed $0.076 \pm$ $0.025 \mathrm{U}$ of Urs were present, i.e. $29.3 \pm 9.8 \%$ (data summarized in Table 1).

The fraction of active Urs units was observed to be higher for CS-Urs in solution compared to free Urs in solution $(29.3 \pm 9.8 \%$ vs. $9 \pm 2 \%)$. One would expect that the restricted diffusion together with deactivation of a fraction of the enzymes due to the coupling chemistry would decrease the efficiency. ${ }^{[31,32]}$ This counter intuitive result may be the result of the increased buffering effect of the CS polymer, maintaining better control of $\mathrm{pH}$ during the reaction as compared to the case of Urs in solution. In the absence of $\mathrm{CS}$, the $\mathrm{pH}$ was observed to increase from 5.5 to 9 at the end of the reaction, while the presence of CS controlled the $\mathrm{pH}$ such that it increased from 5.5 to 6.5 (Figure S5a). At elevated pH, Urs activity is expected to be limited as it has been reported that Urs maintains activity from below $\mathrm{pH} 3$ to 7.5 . $^{[33,34]}$

The GOx / Cat system was similarly evaluated in the microfluidic system, starting with a solution containing $4 \mathrm{mg} \mathrm{mL}^{-1} \mathrm{GOx}$ and $1 \mathrm{mg} \mathrm{mL}^{-1} \mathrm{Cat}+100 \mathrm{mM}$ glucose $(\mathrm{pH} 5.5, \mathrm{NaAc})$. Figure $3 \mathrm{a}$ plots the NMR data, in this case both reactant consumption (glucose) and product formation (D-gluconic acid) could be followed. From the data sheet, $1.265 \pm 0.013 \mathrm{U}$ GOx were anticipated, and from the NMR data $2.9 \pm 0.1 \mathrm{mU}$ were observed $(0.23 \pm 0.01 \%$ active fraction $)$.

To perform the CS-coupled experiments, two polymer solutions were prepared: CS-GOx and CS-Cat. The two polymer solutions were mixed to maintain the $4: 1$ ratio of GOx:Cat, and maintain the expected concentration of GOx at $4 \mathrm{mg} \mathrm{mL}^{-1}$. Finally, the polymer solution was added to a glucose solution $(100 \mathrm{mM})$ before transfer to the microfluidic system and NMR measurement (results in Figure 3b (top), spectra in SI, Figure S9 (a and b)). The active units were determined to be $2.5 \pm 0.6 \mathrm{mU}$, 


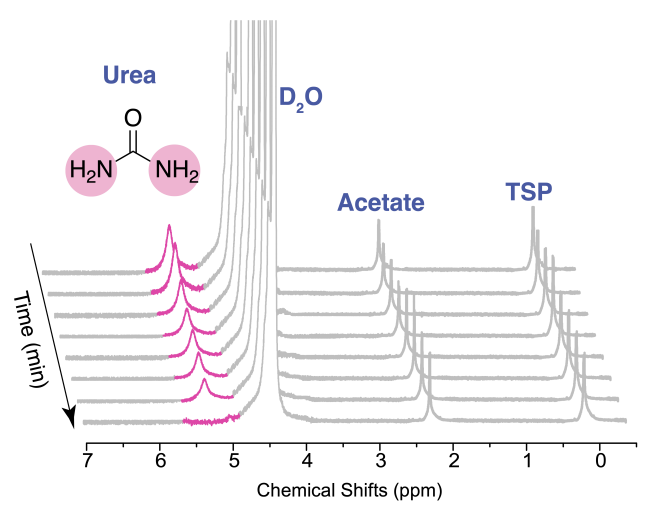

(a)

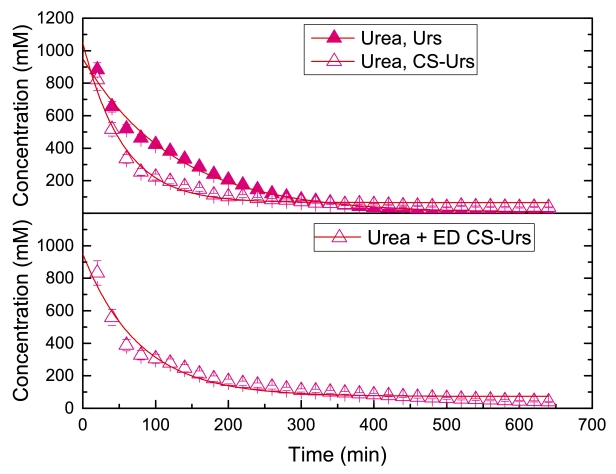

(b)

Figure 2: (a) Representative ${ }^{1} \mathrm{H}$ NMR spectra obtained for the electrodeposited CS-Urs hydrogel. The hydrolysis of urea (highlighted in pink, $5.8 \mathrm{ppm}$ ) is shown as a function of time, and (b) extracted urea concentration in the presence of: top - Urs (open symbols) and CS-Urs (filled symbols) in solution; bottom - immobilized CS-Urs. The urea concentration was calculated using the internal standard (TSP, $50 \mathrm{mM}$ ). The fits to the data were obtained using the Lambert $\mathrm{W}$ function (Equations 1 and 2), kinetic parameters summarized in Table 1. Results for Urs and CS-Urs in solution are plotted in Figure S8.

which was $0.49 \pm 0.12 \%$ of the $519 \pm 14 \mathrm{mU}$ added (after accounting for coupling yield) (data summarized in Table 1).

The fraction of active GOx was observed to be significantly less as compared to Urs, and only up to approximately $70-80 \%$ of the initial glucose was consumed. The solution $\mathrm{pH}$ cannot explain this observation: the optimal $\mathrm{pH}$ for GOx activity is in the range 4.0-7.5 [35,36] $^{[3}$ which was maintained in our system (Figure S5b). A possible explanation for the incomplete substrate conversion is an oxygen deficiency. In the presence of catalase, $0.5 \mathrm{~mol}$ of oxygen is consumed for every mol of glucose. Since the reaction volume was only $3.2 \mu \mathrm{L}$ and the materials used to fabricate the device restrict oxygen diffusion into the solution, oxygen could have become the limiting reagent as the reaction progressed. This is supported by control experiments performed in standard $5 \mathrm{~mm}$ NMR tubes, where the sample volume is $500 \mu \mathrm{L}$ and a large gas headspace is available in the NMR tube. Every other parameter held constant, a factor of 2-4 improvement in the fraction of active units was observed (details in Table S3). This highlights the importance of considering oxygen perfusion in microfluidic devices in cases where it participates in the process. ${ }^{[37]}$

(2) Enzymes immobilized in chitosan hydrogel. To verify the enzymes retained their activity post-electrodepostion, hydrogels were generated using the same CS-enzyme solutions as were functionally verified in solution. For CSUrs, the microfluidic device was filled with a $1 \% \mathrm{w} / \mathrm{v}$ solution and $3 \mathrm{~A} \mathrm{~m}^{-2}$ of current was applied for $15 \mathrm{~min}$ to the electrodes within the channel. Once electrodeposition was complete, the fluidic channel was gently flushed with $200 \mathrm{mM} \mathrm{NaAc}$ and $\mathrm{D}_{2} \mathrm{O}$ to stabilize the hydrogel before introducing a $1000 \mathrm{mM}$ urea solution (in $200 \mathrm{mM} \mathrm{NaAc}$, $\mathrm{pH} 7$ ) to initiate the reaction. For NMR measurements, the sample insert was placed so that the planar electrode did not enter the NMR detection volume. The resulting NMR spectra (one time point every $24 \mathrm{~min}$ ) and extracted concentrations are plotted in $2 \mathrm{a}$ and $\mathrm{b}$ (bottom).

The NMR measurement revealed $0.53 \pm 0.16 \mu \mathrm{U}$ of Urs were present in the system. To estimate the fraction of Urs that was active, it was first necessary to estimate the volume of the hydrogel (details in Supporting Information). Given the dimensions of the planar electrode (circle with radius $0.6 \mathrm{~mm}$ ) and a deposition time 
of 15 min yielding a thickness of $\sim 15 \mu \mathrm{m},{ }^{[25]}$ a volume of $26.5 \pm 0.3 \mathrm{~nL}$ could be estimated. Given the coupling yield was $41 \%$, the fraction of Urs that was active was then $24.4 \pm 7.4 \%$ (summarized in Table 1).

In the case of the GOx and Cat, a two layer hydrogel was generated (multi-layered hydrogels will be denoted as layer-1 / layer-2 / layer-3). Using the same polymer concentration and electrodeposition parameters as for CSUrs, the two layer hydrogel was built by depositing CSGOx, rinsing and stabilization with $200 \mathrm{mM} \mathrm{NaAc}$ buffer in $\mathrm{D}_{2} \mathrm{O}$, then deposition of CS-Cat, followed by rinsing and stabilization so that a CS-GOx / CS-Cat hydrogel was created. To initiate the reaction, $200 \mathrm{mM}$ glucose was flushed into the microfluidic channel (in $200 \mathrm{mM} \mathrm{NaAc}$, pH 7) and NMR measurements were started. The NMR spectra and extracted concentrations (glucose at $5.2 \mathrm{ppm}$, gluconic acid at 4.0, 4.2 ppm) are plotted in Figure $3 \mathrm{a}$ and b (bottom).

As in the case of the Urs hydrogel, GOx was observed to retain its activity when coupled to chitosan and electrodeposited as a hydrogel, as has been reported. ${ }^{[38]}$ The number of active units were determined to be $23 \pm 3 \mathrm{nU}$, with a fractional activity of $0.51 \pm 0.06 \%$ (summarized in Table 1).

Comparison between the chitosan-coupled cases reveals that the activity of both Urs and GOx is not influenced after deposition as a hydrogel. This result is not completely surprising since by definition the hydrogel is highly hydrated, and thus diffusion of the substrate through the polymer network should be minimally restricted.

\section{Multiplexed sensing of enzymatic activity}

Enzyme functionality is maintained after coupling and deposition as a hydrogel. Catalytic cascades also remain active, even when catalytic steps are spatially separated as in the the dual-layer CS-GOx / CS-Cat example. The multilayer hydrogel assembly process was further extended to include multiple, independent catalytic reactions. A three layer hydrogel was deposited with the composition CSUrs / CS-Cat / CS-GOx (schematic Figure 4a). This multiplexed system was prepared using two different electrode geometries, taking advantage of our recent investigation into optimizing electrode placement with respect to the NMR detection volume. ${ }^{[29]}$ The planar geometry, as was used for CS-Urs and CS-GOx / CS-Cat examples, was used to place the catalytic hydrogel assembly slightly upstream (i.e. outside) of the NMR detector. The side-wall electrode geometry, with better NMR performance, was used to place the hydrogel within the NMR detector.

The hydrogel was assembled using the same protocol as described above - for each layer a sequence of CSmodified polymer solution injection into the microfluidic device, electrodeposition for $15 \mathrm{~min}$, and rinsing (using $200 \mathrm{mM}$ NaAc, $\mathrm{pH} 7$ ). The final assembly was then exposed to a solution containing substrates for both Urs and GOx: $1000 \mathrm{mM}$ urea and $100 \mathrm{mM}$ glucose $(200 \mathrm{mM}$ $\mathrm{NaAc}, \mathrm{pH} 7$ ). The ${ }^{1} \mathrm{H}$ NMR spectra and extracted concentration profiles versus time are presented in Figure 4 for both electrode geometries.

The NMR data clearly show the ability to monitor both reactions (urea hydrolysis, glucose oxidation) simultaneously. The substrates (urea, glucose) and product (gluconic acid) all have unique signals that can be used for quantitative determination of the catalytic processes. The extracted kinetic data is summarized in Table 2. Accounting for the expected number of active units within the respective hydrogel layers, the fraction of active enzymes were determined to be essentially independent of hydrogel assembly and electrode geometry (Table 2). A summary of these results is presented in Figure 5.

\section{Enzyme kinetics}

Urease. The initial slope $\left(V_{\max }\right)$ for all Urs measurements were observed to be identical (within our experimental error): $13 \pm 3 \mathrm{mMmin}^{-1}$ for the single layer of CS-Urs, $14.0 \pm 4 \mathrm{mMmin}^{-1}$ for CS-Urs in solution, $15.0 \pm 3 \mathrm{mMmin}^{-1}$ for multi-layer CS-Urs, and $15.0 \pm$ $7 \mathrm{mMmin}^{-1}$ for multiplex CS-enzymes in solution (Table 1). Conversely, the extracted $K_{M}$ value was observed to be dependent on the Urs chemical environment. For a single layer hydrogel of CS-Urs, $K_{M}$ was observed to be $540 \pm 120 \mathrm{mM}$, while for CS-Urs solution, the $K_{M}$ value was $800 \pm 130 \mathrm{mM}$. In the multiplex system, the difference in CS-Urs $K_{M}$ values was less extreme, $400 \pm$ $120 \mathrm{mM}$ for the hydrogel assembly and $360 \pm 100 \mathrm{mM}$ for the multiplexed CS-enyzme in solution (summary of $K_{M}$ ranking: CS-Urs solution $>\mathrm{CS}-\mathrm{Urs}_{\text {gel }}>\mathrm{CS}$-Urs multiplex, gel $_{\text {, }}$ $>$ CS-Urs multiplex, solution). 


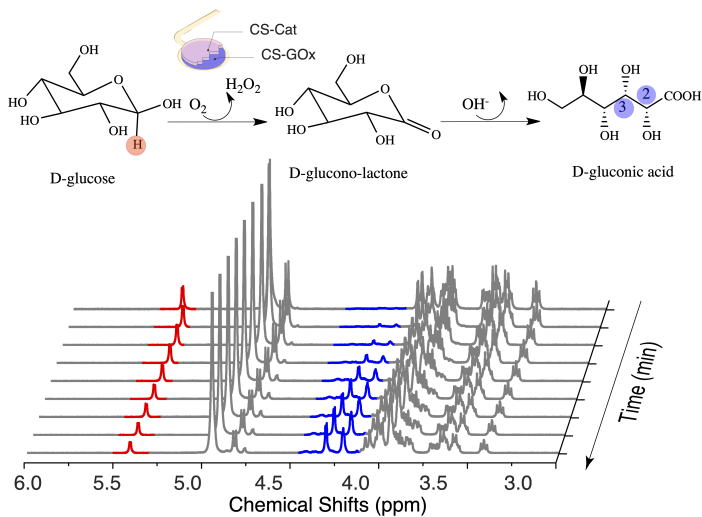

(a)

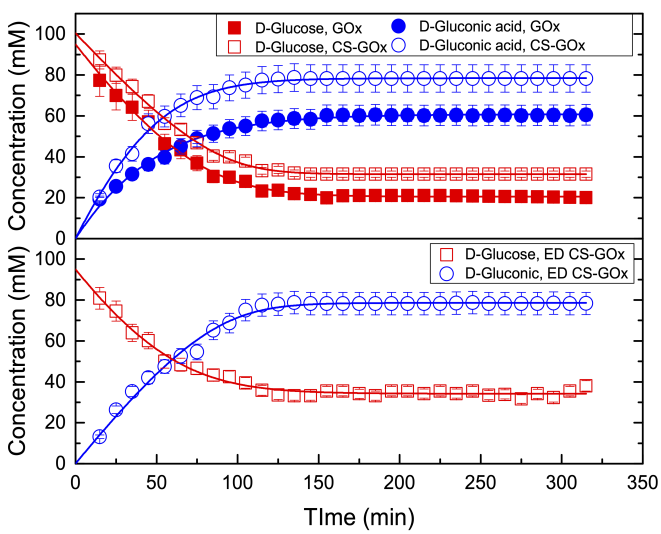

(b)

Figure 3: (a) Representative ${ }^{1} \mathrm{H}$ NMR spectra obtained for the electrodeposited CS-GOx* / CS-Cat hydrogel. Concentrations were determined using the internal reference (TSP, $50 \mathrm{mM}$ ). The depletion of glucose (marked red, $5.8 \mathrm{ppm}$ ) upon conversion to gluconic acid (marked blue, 4-4.2 ppm) is shown as a function of time, and (b) extracted glucose and gluconic acid concentrations in the presence of: top - GOx and Cat in solution (open) and CS-GOx, CS-Cat in solution (filled); bottom - electrodeposited CS-GOx / CS-Cat. Best-fit curves obtained using Equations 1 and 2 are also shown. The resulting kinetic parameters are summarized in Table $1 .{ }^{*}$ GOx experiments were always performed using GOx:Cat in a 4:1 ratio. Results for GOx and CS-GOx in solution are plotted in Figure S9.

The value of $K_{M}$ extracted from these data are approximately 2 orders of magnitude larger than what is reported for jack bean urease (typically $1-4 \mathrm{mM}$ ). ${ }^{[39]}$ For Urs, $K_{M}$ has insignificant variability as a function of $\mathrm{pH},{ }^{[34,40]}$ temperature, ${ }^{[34,41]}$ and pressure. ${ }^{[41]}$ Interpreting $K_{M}$ is in terms of binding affinity, these results suggest that the Urs immobilization significantly influences substrate binding affinity. Immobilization has been observed to affect urease function, ${ }^{[42,43]}$ the degree of influence strongly dependent on the immobilization substrate, chemistry, and measurement conditions. ${ }^{[44]}$ Here, we additionally observe $K_{M} 1000 \pm 230 \mathrm{mM}$ for Urs free in solution (i.e. also uncharacteristically high). As discussed by Stroberg and co-workers, ${ }^{[45]}$ reliable kinetic data can be extracted when i) initial substrate concentration is on the order of $K_{M}$, and ii) initial enzyme concentration is less than $K_{M}$. Under our reaction conditions, [urea $]_{\text {initial }}>>K_{M}$ while the initial enzyme concentration is certainly less than $K_{M}$, casting uncertainty on the extracted values. Inhibition is likely an additional contribution to the observed increase in $K_{M}$ values. Inhibition constants for urea (substrate) and ammonium (product) are in the range $3-6.4 \mathrm{M}$ and $2-118 \mathrm{mM},{ }^{[39]}$ within an order of magnitude of the initial urea concentrations used in these experiments $(1 \mathrm{M})$. This concentration was selected in order to ensure an observable NMR signal, and could be reduced to a value closer to $K_{M}$ and alleviate inhibition to verify this hypothesis, but these experiments were outside the scope of this work.

Glucose oxidase. As in the case of the Urs, the extracted $V_{\max }$ values for GOx was observed to be essentially independent of experimental conditions (note, in all GOx experiments, Cat was maintained at a ratio of 4:1): $0.85 \pm 0.08 \mathrm{mMmin}^{-1}$ for the single layer CS-GOx, $0.87 \pm 0.04 \mathrm{mMmin}^{-1}$ for CS-GOx in solution, $0.9 \pm 0.1 \mathrm{mM} \mathrm{min}^{-1}$ for multi-layered CS-GOx, and $0.9 \pm 0.3 \mathrm{mM} \mathrm{min}^{-1}$ for multiplex CS-enzymes in solution (Table 1). In contrast to the Urs experiments, $K_{M}$ variation was less pronounced for GOx. For the CS-GOx / CS-Cat hydrogel, $K_{M}$ was observed to be $60 \pm 10 \mathrm{mM}$ while for CS-GOx + CS-Cat in solution the value was $80 \pm 20 \mathrm{mM}$. In the multiplex system, $K_{M}$ was $22 \pm 4 \mathrm{mM}$ 


\begin{tabular}{|c|c|c|c|c|c|c|c|c|c|}
\hline \multicolumn{3}{|c|}{ Experiment } & $\begin{array}{l}V_{\max } \\
\mathrm{mM} / \min \end{array}$ & $\begin{array}{l}K_{M} \\
\mathrm{mM}\end{array}$ & $\begin{array}{l}\text { Container } \\
\text { Volume } \\
\text { nl }\end{array}$ & $\begin{array}{l}\text { Coupling } \\
\text { Efficiency } \\
\text { - }\end{array}$ & $\begin{array}{l}\text { Theoretical } \\
\text { Units } \\
\mathrm{mU}\end{array}$ & $\begin{array}{l}\text { Active Units } \\
\mathrm{mU}\end{array}$ & $\begin{array}{l}\text { Active } \\
\text { Fraction } \\
\%\end{array}$ \\
\hline \multirow{6}{*}{$\stackrel{\infty}{\omega}$} & \multirow{4}{*}{ 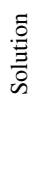 } & Urs + urea & $11+$ & $1000+$ & $3160+3$ & & & & \\
\hline & & CS-Urs + urea & $14 \pm 4$ & $800 \pm 130$ & $3160 \pm 30$ & $0.41 \pm 0.01$ & $259 \pm 7$ & $80 \pm 30$ & $30 \pm 10$ \\
\hline & & $\begin{array}{l}\text { Urs / GOx* + urea, glu- } \\
\text { cose }\end{array}$ & $14 \pm 3$ & $500 \pm 160$ & $3160 \pm 30$ & - & $633 \pm 6$ & $90 \pm 10$ & $14 \pm 2$ \\
\hline & & $\begin{array}{l}\text { CS-Urs / CS-GOx* + } \\
\text { urea, glucose }\end{array}$ & $15 \pm 7$ & $360 \pm 100$ & $3160 \pm 30$ & $0.41 \pm 0.01$ & $259 \pm 7$ & $90 \pm 20$ & $34 \pm 7$ \\
\hline & \multirow{2}{*}{$\overline{0}$} & CS-Urs + urea & $13 \pm 3$ & $540 \pm 120$ & $26.5 \pm 0.3$ & $0.41 \pm 0.01$ & $2.17 \pm 0.06$ & $0.5 \pm 0.2$ & $24 \pm 7$ \\
\hline & & $\begin{array}{l}\text { CS-Urs / CS-GOx* + } \\
\text { urea, glucose }\end{array}$ & $15 \pm 3$ & $400 \pm 120$ & $22.6 \pm 0.2$ & $0.41 \pm 0.01$ & $1.85 \pm 0.05$ & $0.63 \pm 0.09$ & $34 \pm 5$ \\
\hline \multirow{6}{*}{ ơ } & \multirow{4}{*}{ 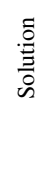 } & GOx + glucose & $0.98 \pm 0.04$ & $280 \pm 70$ & $3160 \pm 30$ & - & $1270 \pm 10$ & $2.9 \pm 0.1$ & $0.23 \pm 0.01$ \\
\hline & & CS-GOx + glucose & $0.87 \pm 0.04$ & $80 \pm 20$ & $3160 \pm 30$ & $0.35 \pm 0.01$ & $440 \pm 10$ & $2.5 \pm 0.6$ & $0.6 \pm 0.1$ \\
\hline & & $\begin{array}{l}\text { Urs / GOx* + glucose, } \\
\text { urea }\end{array}$ & $1.5 \pm 0.5$ & $38 \pm 6$ & $3160 \pm 30$ & - & $1270 \pm 10$ & $5 \pm 3$ & $0.4 \pm 0.2$ \\
\hline & & $\begin{array}{l}\text { CS-Urs / CS-GOx* + } \\
\text { glucose, urea }\end{array}$ & $0.9 \pm 0.3$ & $25 \pm 5$ & $3160 \pm 30$ & $0.35 \pm 0.01$ & $440 \pm 10$ & $2.7 \pm 0.2$ & $0.60 \pm 0.04$ \\
\hline & \multirow{2}{*}{$\bar{\Xi}$} & CS-GOx* + glucose & $0.85 \pm 0.08$ & $60 \pm 10$ & $26.5 \pm 0.3$ & $0.35 \pm 0.01$ & $3.7 \pm 0.1$ & $0.023 \pm 0.003$ & $0.60 \pm 0.07$ \\
\hline & & $\begin{array}{l}\text { CS-Urs / CS-GOx* + } \\
\text { glucose, urea }\end{array}$ & $0.9 \pm 0.1$ & $22 \pm 4$ & $26.5 \pm 0.3$ & $0.35 \pm 0.01$ & $3.7 \pm 0.1$ & $0.024 \pm 0.005$ & $0.6 \pm 0.1$ \\
\hline
\end{tabular}

Table 1: Summary of the kinetic activity of Urease (Urs) and Glucose Oxidase (GOx) using the microfluidic system. Substrate solutions contained either $1000 \mathrm{mM}$ urea, $100 \mathrm{mM}$ glucose (or a mixture thereof), and $50 \mathrm{mM}$ TSP in $200 \mathrm{mM} \mathrm{NaAc}, \mathrm{pH} 7$ buffer. Kinetic parameters were extracted by fitting the consumption of urea and the production of gluconic acid, respectively. A comparison of GOx kinetic parameters using glucose consumption is given in Table S4. *Note: The GOx reactions were always prepared maintaining a 4:1 ratio with Cat.

and $25 \pm 5 \mathrm{mM}$ for the hydrogel and solution cases, respectively. These values compare well with reported values $(33-110 \mathrm{mM}),{ }^{[46,47]}$ suggesting native activity is retained in the immobilized state.

Impact of hydrogel geometry. The extracted kinetic parameters for the two electrode geometries are summarized in Table 2. The $V_{\max }$ values for both Urs and GOx were independent of geometry; however, $K_{M}$ for Urs was significantly different while for GOx, $K_{M}$ was geometry insensitive. As observed in Figure 4, the new feature in the data was the incomplete conversion of urea in the side-wall electrode case. After calculating the number of active Urs units (Table 2), a significant difference between the two geometries is noted $(0.63 \pm 0.09 \mathrm{mU}$ vs. $0.12 \pm 0.03 \mathrm{mU}$ for planar and side wall), and thus the ratio of substrate (urea) to active units was a factor of 5 larger for the side wall case. As a result, we speculate that the inhibitory effect of both the substrate and product was therefore stronger.

\section{Conclusion}

The compositionally customizable microfluidic system described in this study reveals the dynamics of immobilized multiplexed enzymes within an NMR detection volume. The kinetic data for the enzymes Urs and GOx obtained at $303 \mathrm{~K}$ are consistent with Michaelis-Menten kinetics (Equations 1 and 2) at pH 7.0. Each immobilized enzyme (Urs and GOx) performs its selective chemistry independent of the substrate mixture (urea and glucose), as expected. By spatially separating the functionality in the layered hydrogel assembly, new dimensions to studying enzymatic processes are envisioned, for example: (i) by controlling layer thicknesses and chemical identity, mass transit between layers can be tuned; (ii) multi-step chemical conversion can be designed by controlling the spatial location of the relevant catalysts; (iii) more than one independent reaction cascade can be programmed into the hydrogel assembly, enabling multiplexed experiments. In this work, biological catalysis was demonstrated, and this could be extended to homogeneous and heterogeneous catalytic processes in situa- 


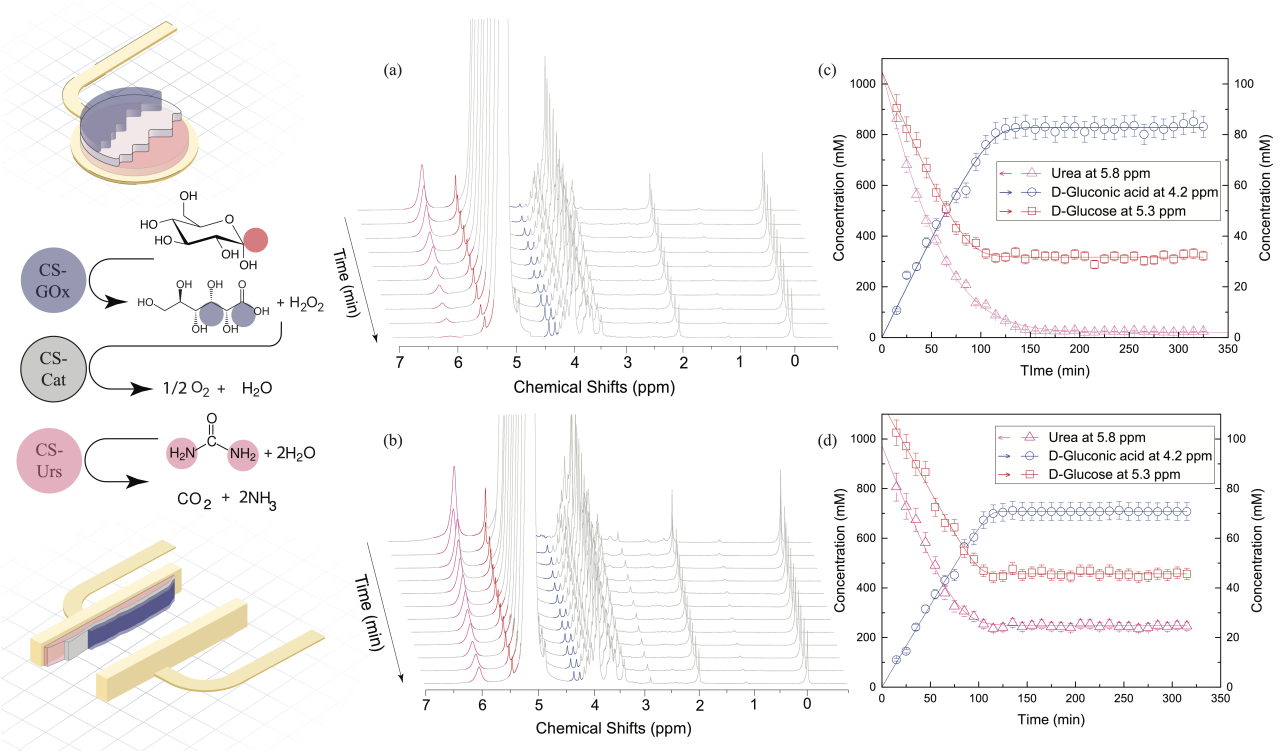

Figure 4: (left side) Illustration of the enzymatic reactions performed with hydrogel immobilized Urs, GOx, and Cat. Position of NMR-integrated hydrogens are highlighted in red (glucose), blue (gluconic acid), and pink (urea). The arrangement of the hydrogel assembly is displayed for the case of a planar electrode (top) and a sidewall electrode (bottom). Gel layers have been colored in blue for CS-GOx, grey for CS-Cat, and pink for CS-Urs. (a and b) Representative ${ }^{1} \mathrm{H}$ NMR time series of Urs and GOx enzymatic reactions. Experiments were performed on (a) a planar electrode and (b) a sidewall electrode. Signals are colored according to the color coding in the left schematic (urea at $5.8 \mathrm{ppm}$, the glucose signal at $5.3 \mathrm{ppm}$, the gluconic acid signal at $4.2 \mathrm{ppm}$ ). (c and d) Concentration time series of reactants and products extracted from NMR spectra in (a) and (b), by integrating NMR signals in the highlighted regions. Left axis: concentration of urea; right axis: concentrations of both glucose and gluconic acid. Solid lines are best-fit curves to the Michaelis-Menten kinetic model (Equations 1 and 2). Kinetic data are summarized in Table 2. Reproducibility is presented in Figure S7. Data for the enzyme mixture in solution, free and CS-coupled, are presented in Figures S10 and S11.

tions where the chemistry is water based (taking advantage of the hydrogel architecture) and the catalyst can be immobilized (chemically or physically) to distinct hydrogel layers. Cases in which the presence of one catalyst is deleterious to the function of another catalyst (e.g. by binding interference) can be additionally considered given the ease of compartmentalization enabled by the layered assembly. Sophisticated multi-functional surfaces can therefore be designed, applicable (non-exclusively) to metabolic engineering, (bio)sensing, and biomimicry investigations.

\section{Experimental Section}

\section{Theoretical basis for progress curve analysis}

Data analysis. NMR data were processed using the TopSpin (Operating and processing software for NMR spectrometers), Matlab2016b and Origin 2016.

The quality and reproducibility of the NMR-based approach to reaction kinetics monitoring depends largely on how reliably the NMR peak area integrals can be converted to concentrations. Here the peak area integrals from recorded ${ }^{1} \mathrm{H}-\mathrm{NMR}$ spectra were converted into concentration values using the known concentration of TSP 


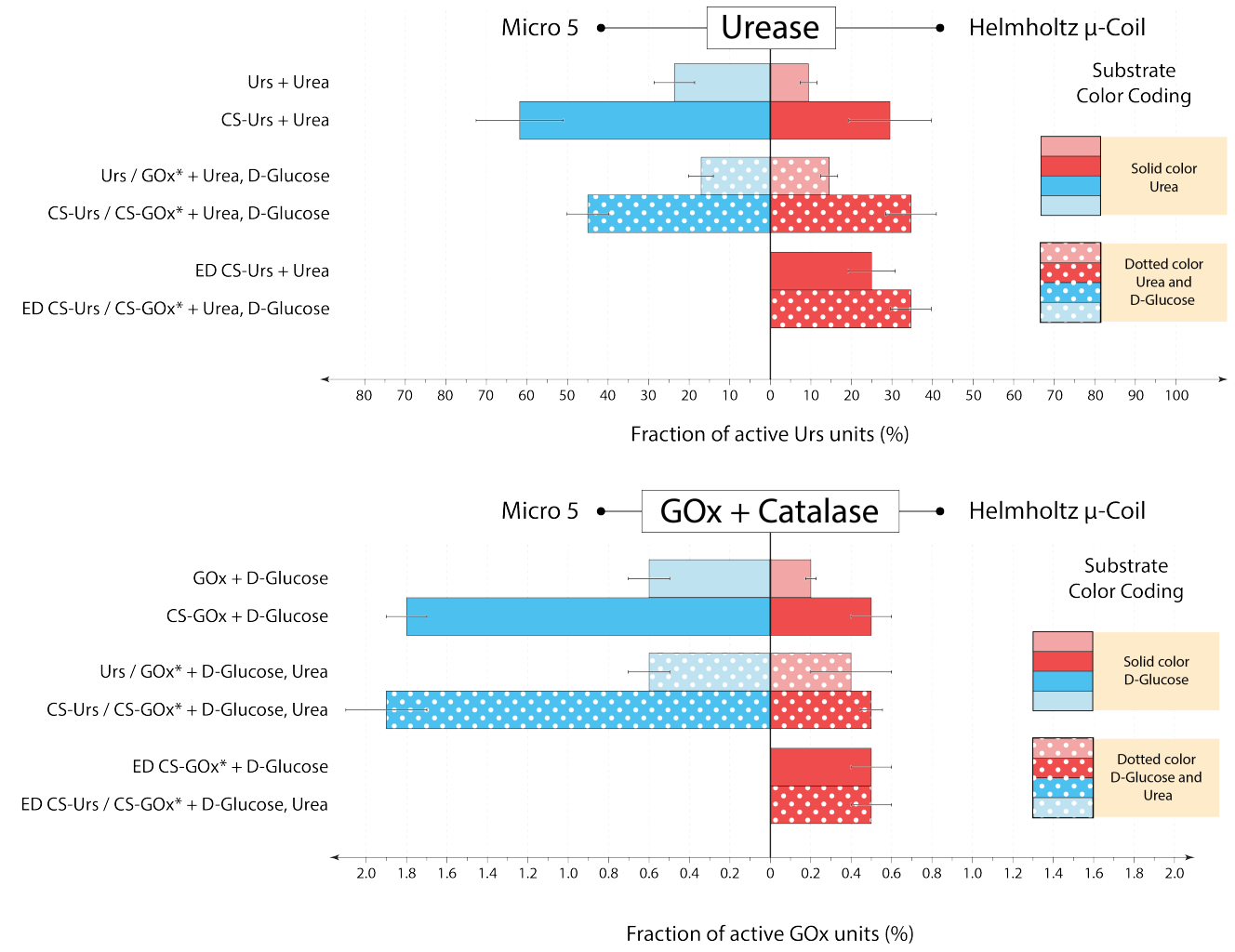

Figure 5: Summary and comparison of the fraction of active enzyme units calculated under the three chemical environments, as well as using two different NMR detectors: standard $5 \mathrm{~mm}$ sample tube, $5 \mathrm{~mm}$ saddle coil; microfluidic system described in this report. Three different subcategories of experiments were grouped, i.e. single enzyme (one enzyme), multiplex (mixed enzymes) in solution, and electrodeposited (ED) multilayered assembly.

added to the sample $([\mathrm{TSP}]=50 \mathrm{mM})$. Determining the molecular concentration using this approach reduces the uncertainties in the quantification of peak areas, since each sample has its own internal TSP reference and allows a comparison of data collected from different experiments. In those cases where the relevant signal overlapped with a larger one (e.g. glucose signals overlapping with the water signal) a non-linear baseline correction was applied before performing signal integration.

The initial slope of the concentration profile $S(t)$, i.e. the reaction velocity at the very beginning of the reaction, was estimated by calculating the numerical derivative of the best fit curve to the Michaelis-Menten model at $S(t)=$ $5 \mathrm{~min}$. The initial concentration parameter $\mathrm{S} 0$ was allowed a $\pm 5 \%$ uncertainty over the nominal initial concentration since there were not enough data points near $S(t)=0$ to allow accurate extrapolation of the intercept when this parameter is allowed to run freely. The reaction velocity extracted from reagent concentration curves and expressed in $\mathrm{mM} / \mathrm{min}$ was converted to $\mu \mathrm{mol} / \mathrm{min}$ using the known volume of either solution or gel containing the enzyme. This operation allows to estimate the absolute amount of product produced per minute, and therefore estimate the units of active enzymes. By definition, a unit (U) of enzyme is the amount required to produce $1 \mu \mathrm{mol}$ of product per minute, under optimal reaction conditions.

Additional reaction kinetics parameters can by extracted from the time-dependent concentration $S(t)$ by us- 


\begin{tabular}{|c|c|c|c|c|c|c|c|}
\hline Experiment & $\begin{array}{l}V_{\max } \\
\mathrm{mM} / \min \end{array}$ & $\begin{array}{l}K_{M} \\
\mathrm{mM}\end{array}$ & $\begin{array}{l}\text { Container } \\
\text { Volume } \\
\text { nl }\end{array}$ & $\begin{array}{l}\text { Coupling } \\
\text { Efficiency } \\
\text { - }\end{array}$ & $\begin{array}{l}\text { Theoretical } \\
\text { Units } \\
\text { mU }\end{array}$ & $\begin{array}{l}\text { Active Units } \\
\mathrm{mU}\end{array}$ & $\begin{array}{l}\text { Active } \\
\text { Fraction } \\
\%\end{array}$ \\
\hline \multicolumn{8}{|c|}{ Planar Electrode } \\
\hline CS-Urs / CS-GOx* & $15 \pm 3$ & $400 \pm 120$ & $22.6 \pm 0.2$ & $0.41 \pm 0.01$ & $1.9 \pm 0.1$ & $0.63 \pm 0.09$ & $34 \pm 5$ \\
\hline CS-Urs / CS-GOx* & $0.9 \pm 0.1$ & $22 \pm 4$ & $26.5 \pm 0.3$ & $0.35 \pm 0.01$ & $3.7 \pm 0.1$ & $0.02 \pm 0.01$ & $0.6 \pm 0.1$ \\
\hline \multicolumn{8}{|c|}{ Sidewall Electrode } \\
\hline CS-Urs / CS-GOx* & $12 \pm 2$ & $130 \pm 80$ & $6.1 \pm 0.3$ & $0.41 \pm 0.01$ & $0.50 \pm 0.01$ & $0.12 \pm 0.03$ & $24 \pm 5$ \\
\hline CS-Urs / CS-GOx* & $1.0 \pm 0.1$ & $23 \pm 8$ & $10.8 \pm 0.5$ & $0.35 \pm 0.01$ & $1.52 \pm 0.05$ & $(8.0 \pm 0.5) \times 10^{-3}$ & $0.54 \pm 0.04$ \\
\hline
\end{tabular}

Table 2: Summary of the kinetic activity of the multi-layered enzymes using two different electrode configurations, planar and sidewall electrodes. Substrate solution composition was $1000 \mathrm{mM}$ urea, $100 \mathrm{mM}$ glucose $(200 \mathrm{mM} \mathrm{NaAc}$, pH $7+50 \mathrm{mM}$ TSP) in each case. Each row reports the extracted data for the enzyme highlighted in bold. *Note: GOx is always prepared together with Cat in a 4:1 ratio.

ing the well established Michaelis-Menten enzyme kinetics model.

For a reagent time series the following equation holds for the time evolution of the concentration $S_{r}(t)$ of a reac$\operatorname{tant}^{[48]}$ :

$$
S_{r}(t)=S_{\infty}+K_{M} W\left[\frac{S_{\infty}-S_{0}}{K_{M}} e^{\frac{\left(S_{\infty}-S_{0}\right)-V_{\max }\left(t-t_{0}\right)}{K_{M}}}\right]
$$

For product concentration $S_{p}(t)$ :

$$
S_{p}(t)=S_{\infty}-K_{M} W\left[\frac{S_{\infty}-S_{0}}{K_{M}} e^{\frac{\left(S_{\infty}-S_{0}\right)-V_{\max }\left(t-t_{0}\right)}{K_{M}}}\right]
$$

where $S_{0}$ is the concentration of reagent at time $t_{0}, S_{\infty}$ is the concentration at the conclusion of the reaction, $K_{M}$ (Michaelis constant) corresponds to the reagent concentration at which half of the enzyme's active sites are occupied, $V_{\max }$ is the maximum reaction velocity. $W$ is the Lambert W-function, the inverse function of $f(W)=$ $W \exp W$. Details about the derivation of Equations 1 and 2 are reported elsewhere. ${ }^{[45]}$

The descriptions of microfluidic fabrication, preparation of the samples and processes for the electrodeposition of chitosan, enzyme coupling and yield quantification, and NMR characterization are available in the Supporting Information.

\section{Acknowledgements}

N.N, H.D, V.B, and N.M. acknowledge funding from the Deutsche Forschungsgemeinschaft for the project BioPRICE (DFG MA 6653/1-1, DFG BA 4275/4-1)), L.B. acknowledges funding from the Carl Zeiss Stiftung. N.N. wishes to thank the University of Malaya and Ministry of Higher Education of Malaysia for the scholarship (SLAB Scheme) and the BioInterfaces International Graduate School (BIF-IGS, www.bif-igs.kit.edu). J.G.K. acknowledges the support from an EU2020 FET grant (TiSuMR, 737043), ERC-SyG (HiSCORE, 951459), the DFG under grant KO 1883/39-1 optiMUM, the framework of the German Excellence Intitiative under grant EXC 2082 "3D Matter Made to Order", and the KIT-VirtMat initiative "Virtual Materials Design II". J.G.K., V.B., and N.M. acknowledge the partial financial support of the Helmholtz Association through the programmes "Science and Technology of Nanosystems - STN", and "BioInterfaces in Technology and Medicine - BIFTM" and "Materials Systems Engineering - MSE'. All Authors would like to acknowledge the support of the Karlsruhe Institute of Technology (KIT), providing the infrastructure to realise this work.

\section{Keywords}

chitosan, urease, glucose oxidase, catalase, conjugation, multiplex, hydrogels, NMR 


\section{References}

[1] S. Ahmed, V. M. Chauhan, A. M. Ghaemmaghami, J. W. Aylott, Biotechnology Letters 2019, 41, 1-25.

[2] M. M.-C. Cheng, G. Cuda, Y. L. Bunimovich, M. Gaspari, J. R. Heath, H. D. Hill, C. A. Mirkin, A. J. Nijdam, R. Terracciano, T. Thundat et al., Current opinion in chemical biology 2006, 10, 11-19.

[3] J. D. Wulfkuhle, L. A. Liotta, E. F. Petricoin, Nature reviews cancer 2003, 3, 267.

[4] L. Hood, J. R. Heath, M. E. Phelps, B. Lin, Science 2004, 306, 640-643.

[5] G. Milcovich, S. Lettieri, F. E. Antunes, B. Medronho, A. C. Fonseca, J. F. Coelho, P. Marizza, F. Perrone, R. Farra, B. Dapas, G. Grassi, M. Grassi, S. Giordani, Adv Colloid Interfac 2017, 249, 163-180.

[6] K. Wang, Y. Hao, Y. Wang, J. Chen, L. Mao, Y. Deng, J. Chen, S. Yuan, T. Zhang, J. Ren, W. Liao, Int J Polym Sci 2019, 2019, 1-14.

[7] S. C. Neves, L. Moroni, C. C. Barrias, P. L. Granja, Trends Biotechnol 2020, 38, 292-315.

[8] S. Mondal, S. Das, A. K. Nandi, Soft Matter 2020 , 16, 1404-1454.

[9] J. Li, S. Wu, E. Kim, K. Yan, H. Liu, C. Liu, H. Dong, X. Qu, X. Shi, J. Shen, W. E. Bentley, G. F. Payne, Biofabrication 2019, 11, 032002.

[10] E. R. Cross, SN Applied Sciences 2020, 2, 397.

[11] Y. Cheng, K. M. Gray, L. David, I. Royaud, G. F. Payne, G. W. Rubloff, Materials Letters 2012, 87, 97-100.

[12] C. Cao, E. Kim, Y. Liu, M. Kang, J. Li, J.-J. Yin, H. Liu, X. Qu, C. Liu, W. E. Bentley, G. F. Payne, Biomacromolecules 2018, 19, 3502-3514.

[13] Y. Cheng, X. Luo, J. Betz, S. Buckhout-White, O. Bekdash, G. F. Payne, W. E. Bentley, G. W. Rubloff, Soft Matter 2010, 6, 3177-3183.
[14] C. Hao, L. Ding, X. Zhang, H. Ju, Analytical chemistry 2007, 79, 4442-4447.

[15] H. Yi, L. Wu, J. J. Sumner, J. B. Gillespie, G. F. Payne, W. E. Bentley, Biotechnology and Bioengineering 2003, 83, 646-52-652.

[16] X. Luo, J. Xu, Y. Du, H. Chen, Analytical Biochemistry 2004, 334, 284.

[17] E. R. Mamleyev, S. Heissler, A. Nefedov, P. G. Weidler, N. Nordin, V. V. Kudryashov, K. Länge, N. MacKinnon, S. Sharma, npj Flexible Electronics 2019, 3, 2 .

[18] W. Shang, C. Chen, K. Lo, G. F. Payne, W. E. Bentley, Sensors Actuators B Chem 2019, 295, 30-39.

[19] Y. Liu, K. Yan, G. Jiang, Y. Xiong, Y. Du, X. Shi, International Journal of Polymer Science 2014, 2014, 1.

[20] P. Zhao, Y. Zhao, L. Xiao, H. Deng, Y. Du, Y. Chen, $\mathrm{X}$. Shi, Colloids and surfaces. B Biointerfaces 2017, $158,474-479$.

[21] K. Yan, Y. Liu, J. Zhang, S. O. Correa, W. Shang, C. Tsai, W. E. Bentley, J. Shen, G. Scarcelli, C. B. Raub, X. Shi, G. F. Payne, Biomacromolecules 2018, 19, 364-373.

[22] S. Wu, K. Yan, J. Li, R. N. Huynh, C. B. Raub, J. Shen, X. Shi, G. F. Payne, React Funct Polym 2020, $148,104492$.

[23] K. Yan, F. Ding, W. E. Bentley, H. Deng, Y. Du, G. F. Payne, X. Shi, Soft Matter 2014, 10, 465-469.

[24] S. Ladet, K. Tahiri, A. Montembault, A. Domard, M. M. Corvol, Biomaterials 2011, 32, 5354-5364.

[25] N. Nordin, L. Bordonali, V. Badilita, N. MacKinnon, Macromolecular bioscience 2019, 19, 1800372.

[26] V. Badilita, R. C. Meier, N. Spengler, U. Wallrabe, M. Utz, J. G. Korvink, Soft Matter 2012, 8, 1058310597.

[27] N. Spengler, J. Höfflin, A. Moazenzadeh, D. Mager, N. MacKinnon, V. Badilita, U. Wallrabe, J. G. Korvink, PloS one 2016, 11, e0146384. 
[28] B. Wu, S. von der Ecken, I. Swyer, C. Li, A. Jenne, F. Vincent, D. Schmidig, T. Kuehn, A. Beck, F. Busse et al., Angewandte Chemie International Edition 2019, 58, 15372-15376.

[29] H. Davoodi, N. Nordin, L. Bordonali, J. G. Korvink, N. MacKinnon, V. Badilita, Lab on a Chip 2020, 20, 3202-3212.

[30] Y. Ogawa, K. Ogawa, B. Wang, E. Kokufuta, Langmuir 2001, 17, 2670-2674.

[31] D. Yang, J. Fan, F. Cao, Z. Deng, J. A. Pojman, L. Ji, RSC advances 2019, 9, 3514-3519.

[32] B. Schmieg, M. Nguyen, M. Franzreb, Frontiers Bioeng Biotechnology 2020, 8, 365.

[33] S. F. Howell, J. B. Sumner, Journal of Biological Chemistry 1934, 104, 619-626.

[34] B. Krajewska, S. Ciurli, Plant Physiology and Biochemistry 2005, 43, 651-658.

[35] J. H. Pazur, K. Kleppe, Biochemistry 1964, 3, 578583.

[36] M.-H. Xue, Q. Xu, M. Zhou, J.-J. Zhu, Electrochemistry communications 2006, 8, 1468-1474.

[37] A. Yilmaz, M. Utz, Lab on a Chip 2016, 16, 2079.

[38] J. Li, D. Maniar, X. Qu, H. Liu, C. Tsao, E. Kim, W. E. Bentley, C. Liu, G. F. Payne, Biomacromolecules 2019, 20, 969-978.

[39] B. Krajewska, Journal of Molecular Catalysis B: Enzymatic 2009, 59, 9-21.

[40] N. E. Dixon, P. W. Riddles, C. Gazzola, R. L. Blakeley, B. Zerner, Canadian journal of biochemistry 1980, 58, 1335-1344.

[41] B. Krajewska, R. van Eldik, M. Brindell, JBIC Journal of Biological Inorganic Chemistry 2012, 17, 1123-1134.

[42] K. Sarfo, H. H. Petach, W. Henderson, Enzyme and microbial technology 1995, 17, 804-808.
[43] J. Chen, S. Chiu, Bioprocess Engineering 1999, 21, 323-330.

[44] Y. Qin, J. Cabral, Biocatal Biotransfor 2009, 20, 114.

[45] Wylie Stroberg and Santiago Schnell, Biophysical Chemistry 2016, 219, 17 - 27.

[46] B. E. Swoboda, V. Massey, Journal of Biological Chemistry 1965, 240, 2209-2215.

[47] Q. H. Gibson, B. E. Swoboda, V. Massey, Journal of Biological Chemistry 1964, 239, 3927-3934.

[48] D. Keilin, E. Hartree, Biochemical journal 1948, 42, 221. 


\section{Supplementary Information}

\section{Microfluidics featuring multilayered hydrogel assemblies enable real-time NMR-monitoring of enzyme cascade reactions}

Nurdiana Nordin, Lorenzo Bordonali, Hossein Davoodi, Novindi Dwi Ratnawati, Gudrun Gygli, Jan G. Korvink, Vlad Badilita*, and Neil MacKinnon*

Compartmentalized chemical reactions at the microscale are interesting from many perspectives including (multi)functional surfaces and biotechnology. Monitoring the molecular content as a measure of functional performance at these small scales is challenging. As a means to address this challenge, we leverage microtechnology and biocompatible materials to integrate a compact, reconfigurable reaction cell featuring electrochemical functionality with high-resolution nuclear magnetic resonance spectroscopy (NMR). We demonstrate the operation of this system by monitoring the activity of enzymes immobilized in chemically distinct layers within a multi-layered chitosan hydrogel assembly. As a benchmark, we observed the parallel activities of urease (Urs), catalase (Cat), and glucose oxidase (GOx) by recording NMR spectra to extract reagent and product concentrations in real-time. As a result, simultaneous monitoring of a cooperative enzymatic process ( $\mathrm{GOx}+\mathrm{Cat})$ together with an independent process (Urs) is achieved. Using Michaelis-Menten progress curve analysis of the NMR data, kinetic data is extracted: in the case of GOx, the Michaelis constants $\left(K_{M}\right)$ are consistent with previous reports, while for Urs, deviations are observed, attributed to an inhibitory effect under our reaction conditions. The system therefore enables the construction of complex reaction cascades with spatial control, as would be interesting in, for example, metabolic engineering and multiplexed sensing applications. 


\section{Table of Contents}

1 Supporting Information 1: Materials and Procedures 2

1.1 Materials .................................2

1.2 Electrode microfabrication . . . . . . . . . . . . . . . . . . . . 2

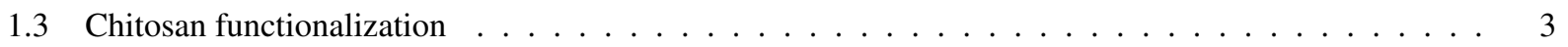

1.4 Enzyme coupling efficiency by UV absorbance . . . . . . . . . . . . . . . . . . . . . . . . . . . . . . . . . . .

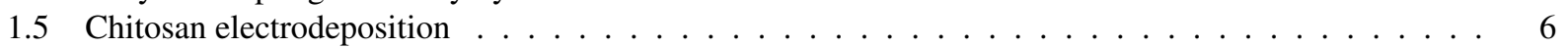

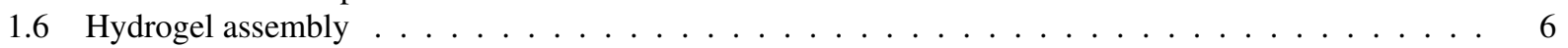

1.7 Enzymatic activity using standard NMR . . . . . . . . . . . . . . . . . . . . 7

1.8 Real-time NMR measurements . . . . . . . . . . . . . . . . . . . . . . 7

2 Supporting Information 2: Results 9

2.1 Sequential electrodeposition of labelled CS using planar and sidewall electrode configurations . . . . 9

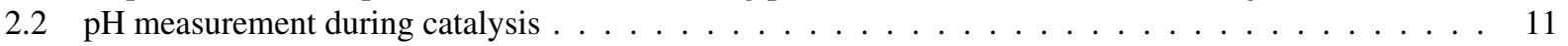

2.3 Calculation of hydrogel volume . . . . . . . . . . . . . . . . . . . . . 11

2.4 Calculation of enzyme active fraction . . . . . . . . . . . . . . . . . . . 11

2.5 Reproducibility . . . . . . . . . . . . . . . . . . . . . . . . . . 12

2.6 Solution experiments using Helmholtz microcoil _. . . . . . . . . . . . . . . . . . . . 14

\section{Supporting Information 1: Materials and Procedures}

\subsection{Materials}

Enzymes: Urease (from Canavalia ensiformis (Jack bean)) with a specific activity of 100,000 U/(g of enzyme) (pH 7.6, $303 \mathrm{~K}, \mathrm{EC} 3.5 .1 .5, \mathrm{MW} \sim 544,620 \mathrm{Da}$ ), glucose oxidase (from Aspergillus niger) with a specific activity of $\geq 100,000$ $\mathrm{U} /(\mathrm{g}$ of enzyme) (type X-S, pH 7.6, $303 \mathrm{~K}, \mathrm{EC} 1.1 .3 .4$, MW 160,000 Da) and catalase (from bovine liver) with a specific activity of lyophilized powder, 2,000-5,000 U/mg protein (EC 1.11.1.6) were purchased from Sigma-Aldrich. Substrates: Urea (powder, BioReagent, for molecular biology, suitable for cell culture), D-glucose ( $\geq 99.5 \%$ (GC)) and glucono- $\delta$-lactone $(\geq 99.0 \%)$ were purchased from Sigma-Aldrich.

NMR solvents: Deuterium oxide $\mathrm{D}_{2} \mathrm{O}$ (99.9 atom \% D), and 3-(trimethylsilyl)- propionic-2,2,3,3- $\mathrm{d}_{4}$ acid sodium salt (99.9 atom \% D, contains 0.05 wt. \% TSP), deuterium chloride (99 atom \% D DCl), and deuterium sodium oxide (99 atom $\% \mathrm{NaOD})$, were purchased from Sigma-Aldrich.

Polymers: chitosan from crab shells (85\% deacetylation, 200kDa), poly(ethylene glycol) bis(carboxymethyl) ether (average MW= 250, PEG), were purchased from Sigma-Aldrich.

Coupling reagents: N-(3-(dimethylamino)propyl)-N-ethylcarbodiimide hydrochloride (EDC) 99\%, N-hydroxysuccinimide (NHS) $97 \%$ were purchased from Sigma-Aldrich.

Buffers: $200 \mathrm{mM}$ of sodium acetate $(\mathrm{NaAc})$ was made with $\mathrm{NaAc}$ tablets in deuterated $\left(\mathrm{D}_{2} \mathrm{O}\right)$ water. The pH was adjusted with deuterium chloride (DCl), and deuterium sodium hydroxide (NaOD). All enzyme and modified-CS solutions and dilutions used this stock buffer to maintain the $\mathrm{pH} 5.5$ (for solution) and $\mathrm{pH} 7$ (for hydrogel) and the same concentration of TSP $(50 \mathrm{mM})$.

\subsection{Electrode microfabrication}

The fabrication process was based on previous work with minor modifications. ${ }^{[29]}$ Briefly, fabrication started with a $210 \mu \mathrm{m}$ thick, 4-inch diameter glass wafer. The substrate was cleaned using a sequence of acetone, isopropanol (IPA), 
and deionized water (DI) baths. An $\mathrm{O}_{2}$ plasma treatment helped to improve wetting of the glass surface by polar photoresists during spin coating. The wafer was further dry-baked on a hotplate at $200{ }^{\circ} \mathrm{C}$ for $5 \mathrm{~min}$. After baking, the substrate was sputtered with two different seed layers of $1 / 2 \mathrm{~nm}$ chromium/gold $(\mathrm{Cr} / \mathrm{Au})$ thickness. The substrate was cleaned again using a sequence of acetone, IPA, and DI baths for $10 \mathrm{~min}$ followed by an $\mathrm{O}_{2}$ plasma treatment.

To define the counter-electrode, SU-8 3025 epoxy-based negative photoresist (UV-exposed regions become crosslinked, unexposed film is washed during development) was coated at $4000 \mathrm{rpm}$ for $60 \mathrm{sec}$, and underwent soft-baking for $12 \mathrm{~min}$ at $95^{\circ} \mathrm{C}$. The dried photoresist was exposed using an i-line mask aligner (MA6, Karl Süss, Germany) with a dose of $350 \mathrm{~mJ} \mathrm{~cm}^{-2}$ at $365 \mathrm{~nm}$ under hard contact, followed by post exposure bake at $95^{\circ} \mathrm{C}$ for $4 \mathrm{~min}$. Development was done using PGMEA developer for $2 \mathrm{~min}$ to achieve the desired undercut. The wafer was washed thoroughly with a sequence of coarse PGMEA, fine PGMEA, and IPA each for $10 \mathrm{~min}$, followed by rinsing using DI water. The substrate was dry baked overnight.

The substrate was then electroplated with Au for 40 min to achieve a target thickness of $2 \mu \mathrm{m}$. SU- 8 was stripped using a microwave plasma etching. A secondary SU-8 layer was spincoated and patterned to develop the thin structures, e.g., the working electrodes, access pads, the tracks. A similar lithography procedure was performed to produce a cover layer for the thin structures. The unprotected gold seed layer was etched by gold etchant for $60 \mathrm{sec}$ followed by $\mathrm{Cr}$ etching using chromium etchant for $60 \mathrm{sec}$. The substrate was rinsed with DI water and SU-8 was stripped.

Ordyl SY390 (Elga Europe s.r.l., Italy) DFR was used to define the fluidic channel side walls, following a reported protocol. ${ }^{[2]}$ The surface of the wafer was first activated in an $\mathrm{O}_{2}$-plasma cleaner at $0.3 \mathrm{mbar}, 40{ }^{\circ} \mathrm{C}$ and $20 \mathrm{~W}$ at $40 \mathrm{kHz}$ to improve the adhesion of the first laminated layer. Four fresh layers of Ordyl were laminated onto the glass substrate using a standard lamination device (Mylam 12, GMP) at $85^{\circ} \mathrm{C}$ and roll speed $1 \mathrm{~cm} \mathrm{~s}^{-1}$, resulting in a total nominal resist thickness of $90 \mu \mathrm{m}$. A 1 min post-lamination bake was performed at $85^{\circ} \mathrm{C}$ on a hotplate. The Ordyl stack was then exposed to $365 \mathrm{~nm} \mathrm{UV} \mathrm{light} \mathrm{for} \mathrm{a} \mathrm{total} \mathrm{dose} \mathrm{of} 180 \mathrm{~mJ} \mathrm{~cm}^{-2}$ at $365 \mathrm{~nm}$. A post exposure bake was performed for 1 minute at $85^{\circ} \mathrm{C}$.

The Ordyl patterns were developed for $5 \mathrm{~min}$ in Ordyl developer under ultrasonic agitation. The developed structures were rinsed in IPA and DI water and dried under nitrogen flow. Bonding to a $210 \mu \mathrm{m}$ thick top glass wafer was achieved using a hot embossing device (EVG 510HE) with an applied pressure of $\sim 6 \mathrm{bar}$, at a temperature of $95^{\circ} \mathrm{C}$ for 30 minutes. Inlet and outlet holes were drilled into the top glass wafers before bonding, by machining the thin glass with a nanosecond UV laser (PIRANHA® ACSYS) pulsed at $30 \mathrm{kHz}$. The entire fabrication process is illustrated in Figure S1.

The sidewall electrode microfluidic device was fabricated as described previously. ${ }^{[29]}$

\subsection{Chitosan functionalization}

Chitosan modification was always performed in solution (i.e. $\mathrm{pH}$ 5.0). After each modification, the resulting polymer was purified by precipitation with $\mathrm{NaOH}$ and dialysis against PBS ( 3 fold by volume) for at least one day at $4{ }^{\circ} \mathrm{C}$ before either the next coupling reaction, chemical analysis, or electrodeposition.

Polyethylene glycol (PEG) coupling. Chitosan was coupled with PEG featuring diacid functionality as described previously. ${ }^{[25]}$ PEG was activated with EDC and NHS in $20 \mathrm{~mL}$ of deionized water for 30 minutes at $24{ }^{\circ} \mathrm{C}$. The PEG:EDC:NHS ratios were 1:0.5:0.5. This solution was then added to a $1 \% \mathrm{w} / \mathrm{v}$ chitosan solution containing the appropriate quantity of amine reaction centers (PEG:CS-amine 1:1). The reaction was allowed to proceed for 3 hours at $24^{\circ} \mathrm{C}$ before purification.

Quantum dot coupling. To aid in hydrogel layer visualization, quantum dot (QD) fluorescence was used. CS-QD samples were prepared as described previously. ${ }^{[25]}$

Enzyme coupling. After dialysis of CSPEG, $0.6 \mathrm{~g}$ CSPEG hydrogel were weighed. This amount was chosen because of its good solubility in $3 \mathrm{~mL}$ of $\mathrm{D}_{2} \mathrm{O}$. The CSPEG was activated with EDC and NHS in $1 \mathrm{~mL}$ deionized water for 30 minutes at $24^{\circ} \mathrm{C}$. The ratios CSPEG:EDC:NHS were set to 1:0.5:0.5. Then each enzyme (Urs: $2 \mathrm{mg}$; GOx: $4 \mathrm{mg}$; 


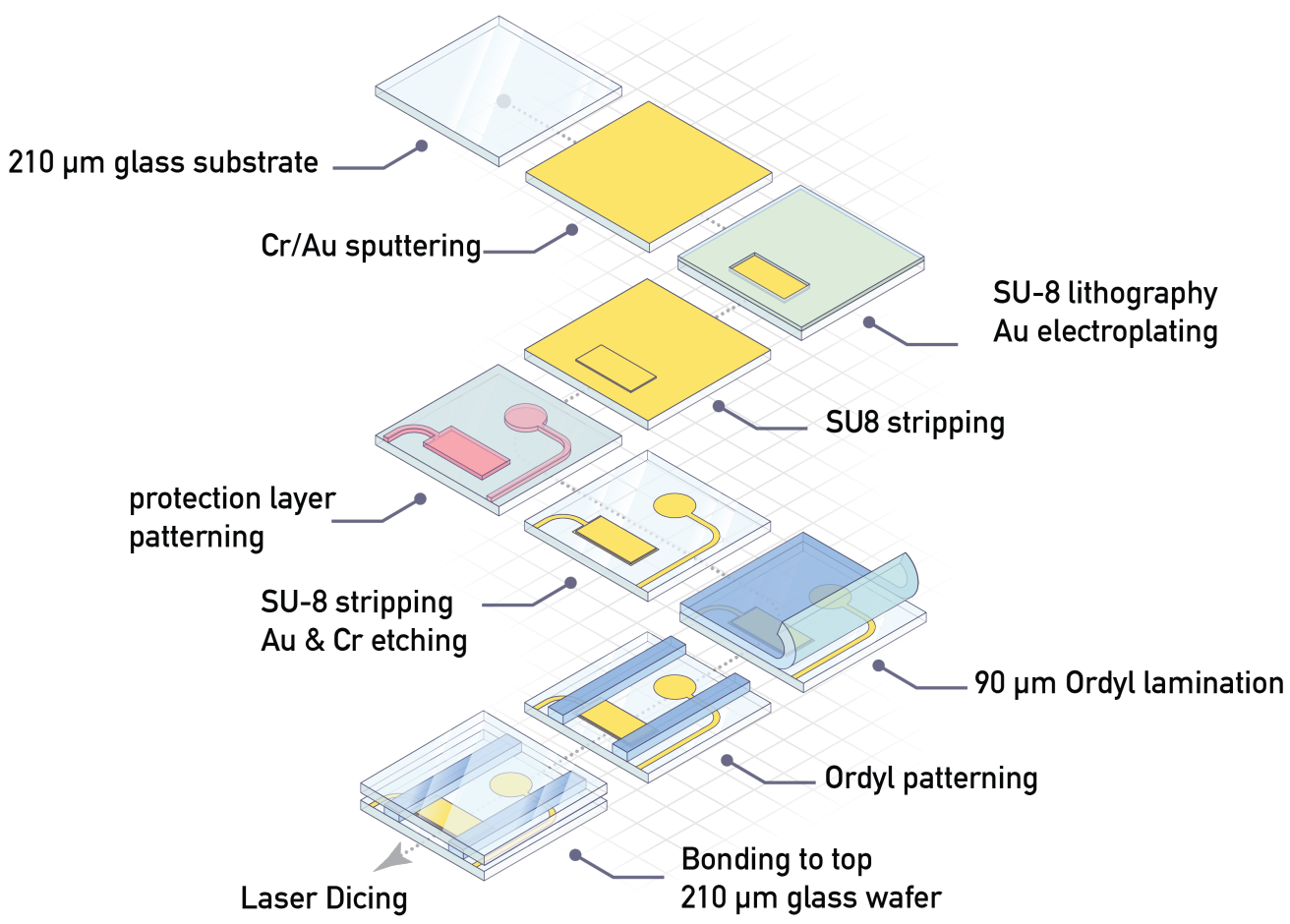

Figure S1: Illustration of the fabrication process for the planar electrode microfluidic platform with two different thicknesses of the working electrode, $3 \mathrm{~nm}$ and $34 \mathrm{~nm}$ Au. Each gold working electrode covers a nominal area of $1.76 \mathrm{~mm}^{2}$.

catalase: $1 \mathrm{mg}$ ) was mixed with this solution in a separate vial. The reaction was carried out at $24{ }^{\circ} \mathrm{C}$ for 3 hours before a purification step. Purification was performed by overnight dialysis of the solution with PBS.

For the kinetic study involving Urs, $0.6 \mathrm{~g}$ of enzyme-bound CSPEG hydrogel (CSPEG-Urs) were weighed. The final sample was prepared by transferring $1 \mathrm{~mL}$ of the $1000 \mathrm{mM}$ urea stock solution into an Eppendorf vial containing the CSPEG-Urs hydrogel. $500 \mu \mathrm{L}$ of the obtained solution were transferred into an NMR tube. A timer was started at this point to track the inter-time $t_{0}$ between the start of the reaction and the acquisition of the first NMR spectrum. The same procedure was followed for kinetic studies of the GOx enzyme, mixing 0.6 g (CSPEG-GOx, CSPEG-cat) of hydrogel with $1 \mathrm{~mL} 100 \mathrm{mM}$ of D-Glucose stock solution.

\subsection{Enzyme coupling efficiency by UV absorbance}

To determine the coupling efficiency of each enzyme to CSPEG, we performed UV absorbance measurements on samples containing the modified polymer and the enzyme. First, six different concentrations of free enzymes (Urs and GOx) were measured in three repeated experiments, as shown in Figure S2a and d. A series of six CSPEG-enzyme samples were prepared at various initial enzyme concentrations. After purification, UV absorbance was measured of the CSPEG-enzyme solution, as plotted in Figure S2b and e. To estimate the coupling yield, the absorbance measure- 
ment of the CSPEG-enzyme was compared to the calibration plot obtained using free enzymes in solution. In the work reported in the main text, Urs was coupled to CS using an initial enzyme concentration of $2 \mathrm{mg} \mathrm{mL}^{-1}(3.7 \mu \mathrm{M})$, while GOx coupling was performed at $4 \mathrm{mg} \mathrm{mL}^{-1}(25 \mu \mathrm{M})$. The quantitiy bound under these initial conditions is highlighted by the arrows in Figure S2c and f. The resulting estimated coupling efficiency for Urs and GOx were 41\% and 35\%, respectively.

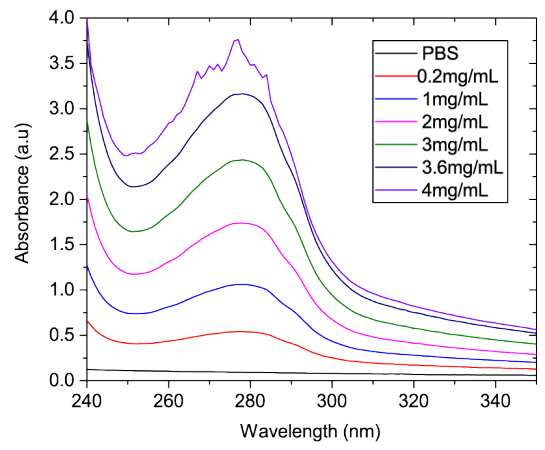

(a)

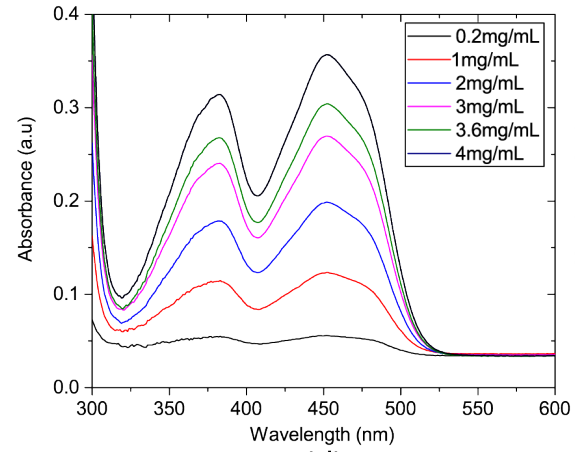

(d)

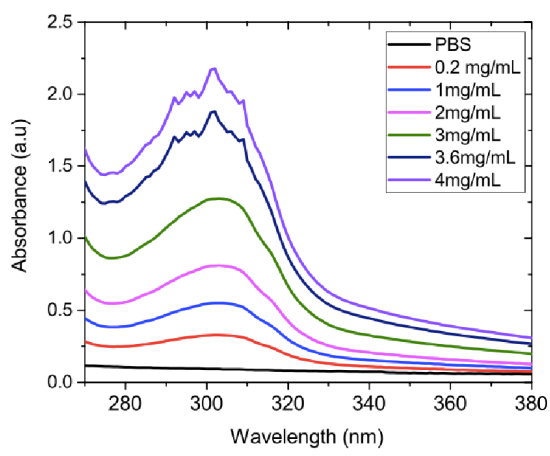

(b)

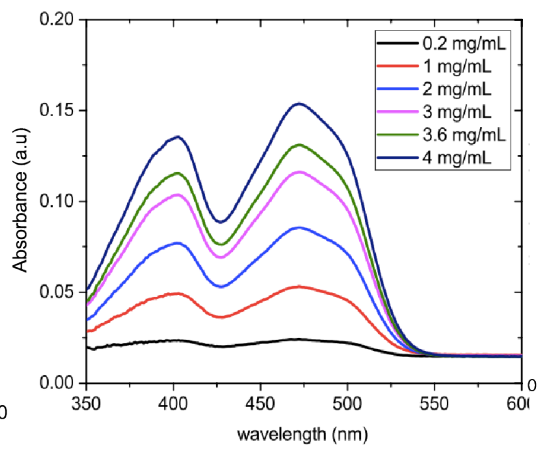

(e)

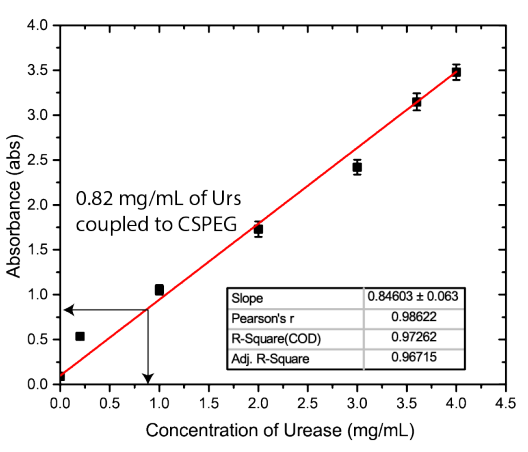

(c)

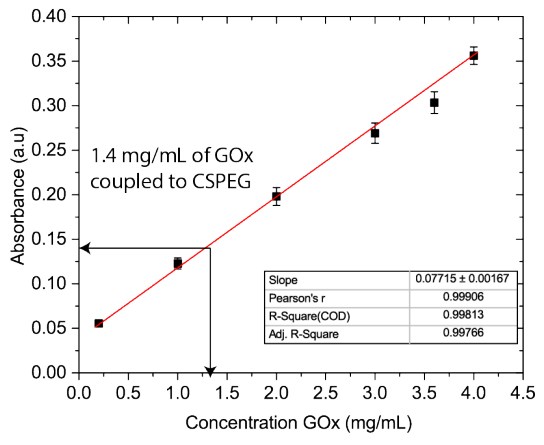

(f)

Figure S2: UV absorption spectra of (a) Urs, (d) GOx free in solution; (b) CS-Urs, (e) CS-GOx after coupling using the initial enzyme concentrations noted in the legend; (c) Urs and (f) GOx absorbance plots of the six calibration solutions (mean \pm standard deviation of three replicates). Arrows indicate the absorbance of the purified CS-enzyme measured at the initial enzyme concentration used throughout this work $\left(2 \mathrm{mg} \mathrm{mL}^{-1} \mathrm{Urs}, 4 \mathrm{mg} \mathrm{mL}^{-1} \mathrm{GOx}\right)$. Absorbance was measured at $280 \mathrm{~nm}$ (Urs, solution), $380 \mathrm{~nm}$ (GOx, solution), $300 \mathrm{~nm}$ (CS-Urs), and $400 \mathrm{~nm}$ (CS-GOx). 


\subsection{Chitosan electrodeposition}

The chitosan solution $(1 \% \mathrm{w} / \mathrm{v}, \mathrm{pH} 5.5)$ was prepared by dissolving chitosan in a diluted $\mathrm{HCl}(0.2 \mathrm{M})$ solution as previously described. ${ }^{[4,25]}$ The solution was filtered through a $5 \mu \mathrm{m}$ syringe filter before use.

The channel was first cleaned with ethanol and washed thoroughly with DI water, followed by drying under nitrogen stream. Chitosan electrodeposition was performed in open and a closed configuration. The open configuration allowed for profilometric measurement of hydrogel height, while all NMR experiments were done using the closed configuration. In the open configuration the electrode array was directly exposed to the chitosan solution whereas in the closed system the chitosan solution was injected into the fluidic channel enclosing the electrode array. The electrodes were connected to a precision current source using the on-chip gold metal pads.

A PID-stabilized current density of $\sim 3 \mathrm{~A} / \mathrm{m}^{2}$ was run through the chosen electrode pair for a certain time to obtain a deposited layer of desired height. After electrodeposition, the chitosan solution was flushed and the deposited assembly was rinsed with DI water.

\subsection{Hydrogel assembly}

To ensure consistency in experimental conditions, the preparation of solution containing the enzymes and either coupling or not coupling to the CSPEG polymer were carried out according to the same protocol as we carried out using a standard $5 \mathrm{~mm}$ NMR saddle coil, except for the final target sample volume. In this case the sample volume is defined by the fluidic channel of the sample insert, that is $3.2 \mu \mathrm{L}$ for planar electrode and wide channel sidewall electrode configurations, and $2.5 \mu \mathrm{L}$ for the narrow channel sidewall electrode.

Relevant sample solutions:

- Solution A: $1000 \mathrm{mM}$ urea

- Solution B: $100 \mathrm{mM}$ glucose

- *Solution C: $35 \mu \mathrm{M}$ CS-Urs (15 U in $10 \mu \mathrm{L})$

- *Solution D: $20 \mu \mathrm{M}$ CS-Cat (1 U in $10 \mu \mathrm{L})$

- *Solution E: $32 \mu \mathrm{M}$ CS-GOx (10 U in $10 \mu \mathrm{L})$

(*Note:This is the expected number of units assuming 100\% coupling yield)

A stock solution of $200 \mathrm{mM} \mathrm{NaAc}$ buffer at $\mathrm{pH}$ 7, and $50 \mathrm{mM}$ TSP as NMR internal reference was used to prepare Solutions A and B to stabilise the $\mathrm{pH}$ and provide an NMR chemical shift reference at $0 \mathrm{ppm}$. Solutions C, D and E were filtered through a $5 \mu \mathrm{L}$ polycarbonate filter, and filled into three separate syringes.

Electrodeposition of the CS-Urs layer: Solution $\mathrm{C}$ was injected into the microfluidic channel, then electrodeposition was carried out for 15 minutes by running a PID-stabilized DC-current (current density of $3 \mathrm{~A} / \mathrm{m}^{2}$ ) through the chosen electrode pair to obtain a deposited layer of desired height $(15-20 \mu \mathrm{m})$. After electrodeposition, the enzyme solution was flushed and the channel was rinsed with $\mathrm{D}_{2} \mathrm{O}$. Then Solution A was injected and the inlet and outlet were immediately sealed. The sample insert was then mounted on the probe and the probe was transferred to the NMR magnet for real-time monitoring. The same procedure was followed by for deposition of solutions D and $\mathrm{E}$.

Electrodeposition of multilayered chitosan assembly: the assembly was prepared using the following protocol: 1 ) injection of solution $C$, 2) electrodeposition $+\mathrm{D}_{2} \mathrm{O}$ rinsing, 3) injection of solution $\mathrm{D}$, 3) electrodeposition $+\mathrm{D}_{2} \mathrm{O}$ rinsing, 4) injection of solution $\mathrm{E}, 5)$ electrodeposition $+\mathrm{D}_{2} \mathrm{O}$ rinsing. Each deposition step was carried out for 15 minutes with the same current density $\left(3 \mathrm{~A} / \mathrm{m}^{2}\right)$ to obtain a deposited layer of the desired height $(15-20 \mu \mathrm{m})$. 
Once the assembly was complete, a solution containing all substrates (1000 mM urea, $100 \mathrm{mM}$ glucose, $50 \mathrm{mM}$ TSP) was injected into the microfluidic chip, the inlet and outlet were immediately sealed, and the sample insert was then mounted on the probe and the probe was transferred to the NMR magnet for real-time monitoring.

\subsection{Enzymatic activity using standard NMR}

Enzyme in solution: two different samples were used in a standard $5 \mathrm{~mm}$ NMR tubes. The first sample was used to adjust the NMR parameters. These samples contained only the substrate, prepared in Eppendorf vials starting from a $1000 \mathrm{mM}$ urea and a $200 \mathrm{mM}$ glucose stock solution (in $200 \mathrm{mM} \mathrm{NaAc}$ buffer, $\mathrm{pH}$ 7.0). For urea samples the stock was used to prepare $1000 \mathrm{mM}, 500 \mathrm{mM}, 250 \mathrm{mM}$ and $100 \mathrm{mM}$ samples with a final volume of $1 \mathrm{~mL}$ each. For glucose samples, the stock solution was diluted to $100 \mathrm{mM}, 50 \mathrm{mM}, 30 \mathrm{mM}$ and $10 \mathrm{mM}$ with a final volume of $1 \mathrm{~mL}$ each. A $500 \mu \mathrm{L}$ volume was taken from each sample and transferred to a $5 \mathrm{~mm}$ NMR tube.

The second sample was dedicated to the kinetic experiments. It contained $1000 \mathrm{mM}$ urea and $2.0 \mathrm{mg} / \mathrm{mL}(3.7 \mu \mathrm{M})$ urease. The sample was prepared by transferring $1 \mathrm{~mL}$ of the $1000 \mathrm{mM}$ urea stock solution into an Eppendorf vial loaded with $2 \mathrm{mg}$ dry stock enzyme. After thorough mixing, $500 \mu \mathrm{L}$ of the solution were transferred to an NMR tube for acquisition. A timer was started immediately after mixing the stock solution with the dry enzyme to track the time between the start of the enzymatic reaction and the acquisition of the first usable NMR spectrum. We labelled this intertime as $T_{0}$. The same procedure was used for the kinetic study of the GOx enzyme. In this case a stock solution with $100 \mathrm{mM}$ glucose was prepared and $1 \mathrm{~mL}$ of the stock were mixed with $3 \mathrm{mg} / \mathrm{mL}(19 \mu \mathrm{M})$ dry GOx and $1 \mathrm{mg} / \mathrm{mL}$ catalase in an Eppendorf vial.

Enzymes coupled to chitosan: after dialysis of CS-modified polymer, $0.6 \mathrm{~g}$ of the hydrogel were weighed. The final sample was prepared by transferring $1 \mathrm{~mL}$ of the $1000 \mathrm{mM}$ urea stock solution (in $200 \mathrm{mM}$ NaAc buffer, $\mathrm{pH}$ 5.5) into an Eppendorf vial containing the CS-Urs hydrogel. $500 \mu \mathrm{L}$ of the obtained solution were transferred into an NMR tube. A timer was started immediately after mixing to track the time $\mathrm{T}_{0}$ between start of the reaction and acquisition of the first NMR spectrum. The same procedure was followed for kinetic studies of the GOx enzyme, mixing $0.6 \mathrm{~g}$ (CS-GOx, CS-Cat) hydrogel with $1 \mathrm{~mL} 100 \mathrm{mM}$ glucose stock solution.

\subsection{Real-time NMR measurements}

A custom designed NMR probe was employed featuring the integration of all sub-assemblies and providing the external connections for fluidics and NMR signal lines. The diameter was constrained by the magnet bore, a $500 \mathrm{MHz}$ wide bore system (Bruker BioSpin, Rheinstetten) with a bore diameter of $72.9 \mathrm{~mm}$. To provide flexibility for the fluidic interconnections we integrated a feed-through system that enabled the integration of tubings of variable diameters and established the connections of the micro-detector with the external control and supply components.

The probe was equipped with the required mechanical, electrical and fluidic connections to accommodate a commercial 3-axis micro gradient system. For final experimental installation, the gradient was slipped over the probe head and a tight mechanical locking mechanism ensured the rigid mounting of the probe head to the probe. The interface for the exchangeable NMR probe head provided the contacts for the ${ }^{1} \mathrm{H}$ RF channel. The probe was equipped with two additional high quality air trimmer capacitors (TG 092 Temex-Ceramics) that established a low loss interface between the $50 \Omega$ transmission line and the RF resonator. A non-conducting glass fibre rod was mounted on each trimmer capacitor which enabled to conduct a final tuning and matching procedure once the final assembly was mounted into the MR scanner.

The experiments were performed with two different NMR coils. As a reference, control experiments were performed using a standard $5 \mathrm{~mm}$ saddle coil insert and Micro 5 micro-imaging probe (Bruker). Microfluidic experiments 
were performed using a $1.2 \mathrm{~mm}$ Helmholtz microcoil. ${ }^{[5]}$ Electrodeposition of the CS-enzymes was performed outside of the magnet.

As control experiments, a one-dimensional (1D) NMR experiments were performed on the substrate (urae, glucose) and product (gluconic acid) solutions at $20^{\circ} \mathrm{C}$ to identify the relevant signals. A standard pulse calibration sequence (nutation sequence) was performed to determine the $90^{\circ}$ pulse. All chemical shifts are expressed in units of parts per million ( $\mathrm{ppm}$ ) with respect to TSP (0 ppm). Each 1D NMR spectrum was collected with a spectral width of $18.93 \mathrm{ppm}$ (9469.70 hertz) over 34,000 data points for a total FID measurement time of $1.80 \mathrm{~s}$. The relaxation delay was set to $1 \mathrm{~s}$, to ensure that as many intermediate spectra as possible could be recorded before the complete enzymatic conversion of urea into the products. Averaging was performed with 8 scans for saddle coil and 200 scans for the Helmholtz microcoil. For the real-time measurements, the experiment was set up to collect FIDs continuously in order to follow the reaction. A delay of 10 minutes was added between NMR acquisitions, to allow for a reasonable time resolution and to limit the amount of data points (spectra) to be post-processed. This delay was added for convenience and could certainly be neglected in case higher time resolution is required.

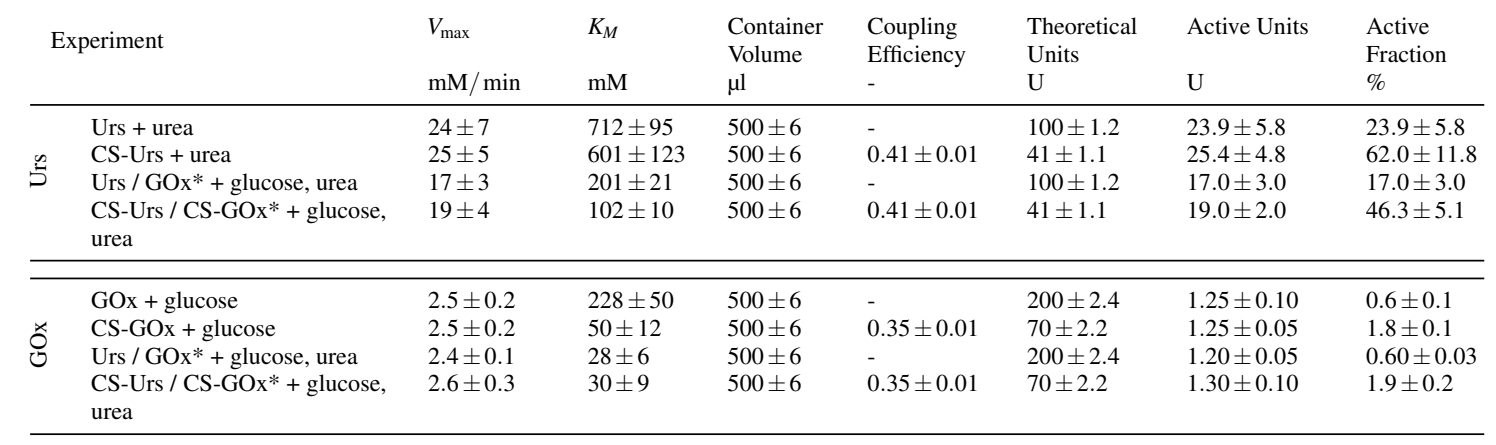

Table 3: Summary of the kinetic activity of Urease and Glucose Oxidase using using the commercial $5 \mathrm{~mm}$ saddle coil. Kinetic parameters were extracted by fitting the consumption of urea and the production of gluconic acid, respectively. *Note: reactions of GOx were always done together with Cat in a 4:1 ratio.

\begin{tabular}{|c|c|c|c|c|c|}
\hline \multirow[b]{2}{*}{ Experiment } & & \multicolumn{2}{|c|}{ Gluconic acid } & \multicolumn{2}{|c|}{ Glucose } \\
\hline & & $\begin{array}{l}V_{\max } \\
\mathrm{mM} / \min \end{array}$ & $\begin{array}{l}K_{M} \\
\mathrm{mM}\end{array}$ & $\begin{array}{l}V_{\max } \\
\mathrm{mM} / \min \end{array}$ & $\begin{array}{l}K_{M} \\
\mathrm{mM}\end{array}$ \\
\hline \multirow{4}{*}{ Solution } & GOx+D-Glucose & $0.98 \pm 0.04$ & $280 \pm 70$ & $1.8 \pm 0.8$ & $110 \pm 40$ \\
\hline & CS-GOx+D-Glucose & $0.87 \pm 0.04$ & $80 \pm 20$ & $1.5 \pm 0.2$ & $35 \pm 10$ \\
\hline & Urs/GOx+D-Glucose, Urea & $1.5 \pm 0.5$ & $38 \pm 6$ & $0.9 \pm 0.1$ & $37 \pm 6$ \\
\hline & CS-Urs / CS-GOx + D-Glucose, Urea & $0.9 \pm 0.3$ & $25 \pm 5$ & $0.9 \pm 0.1$ & $22 \pm 3$ \\
\hline \multirow{2}{*}{ Hydrogel } & CS-GOx+D-Glucose & $0.85 \pm 0.05$ & $60 \pm 10$ & $1.03 \pm 0.09$ & $16 \pm 4$ \\
\hline & CS-Urs / CS-GOx + D-Glucose, Urea & $0.9 \pm 0.1$ & $22 \pm 4$ & $1.0 \pm 0.2$ & $7 \pm 2$ \\
\hline Planar electrode & CS-Urs / CS-GOx & $0.9 \pm 0.1$ & $22 \pm 4$ & $1.0 \pm 0.2$ & $7 \pm 2$ \\
\hline Sidewall electrode & CS-Urs / CS-GOx & $0.8 \pm 0.1$ & $23 \pm 8$ & $1.7 \pm 0.8$ & $25 \pm 5$ \\
\hline
\end{tabular}

Table 4: Comparison of the GOx kinetic parameters extracted using the Michaelis-Menten progress curve fitting based on either gluconic acid production or glucose consumption. 


\section{Supporting Information 2: Results}

\subsection{Sequential electrodeposition of labelled CS using planar and sidewall electrode config- urations}
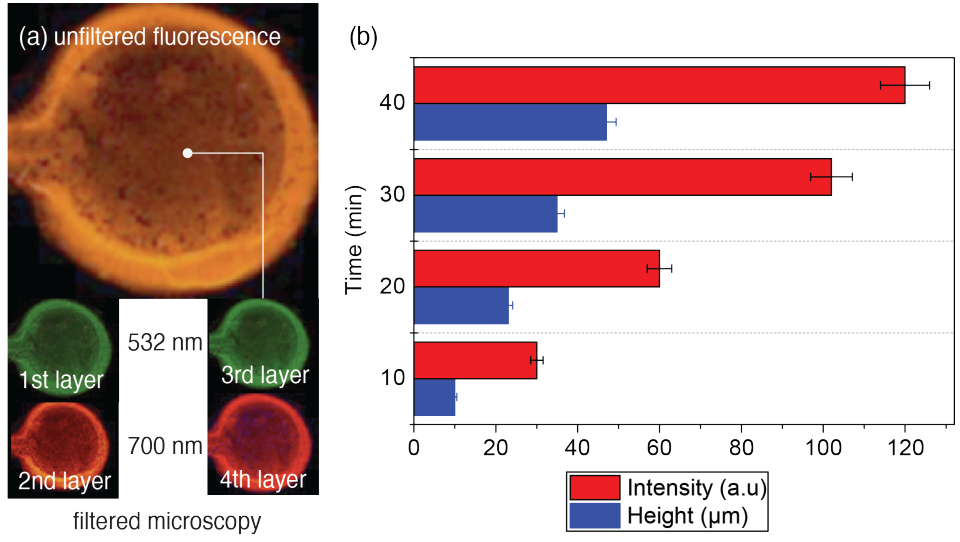

Figure S3: (a) Unfiltered (top) and filtered (bottom) fluorescence microscopy images and (b) mean profile height and fluorescence intensity charts versus deposition time as measured by profilometry and fluorescence microscopy for a three-step sequential electrodeposition of chitosan over 40 minutes total deposition time. A total of four hydrogel layers of QD-labelled chitosan $\left(\lambda_{\text {emission }}=532 \mathrm{~nm} ; 560 \mathrm{~nm} ; 700 \mathrm{~nm}\right)$ were assembled

Planar electrodes: three layers of CS-QD were assembled as shown in Figure S3a with a 20 minute deposition time for each layer at a current density of $3 \mathrm{~A} / \mathrm{m}^{2}$.

The fluorescence intensity from the gel layers was visualized layer by layer using fluorescence microscopy and the mean intensity was extracted using ImageJ. The intensity was then plotted versus time of deposition (Figure S3b). Meanwhile, to determine the thickness of the individual layers, the upper glass was removed from the platform to measure the thickness of the hydrogel layers using a profilometer. The results of the thickness measurement are shown in Figure S3b.

According to Figure S3b, for every 20 minutes of deposition, the thickness increased by 20-25 microns, together with a proportional increase in the mean fluorescence intensity, whereby the average intensity increased by a factor of 2. Individual layers can be visualized using an emission band pass filter, so long as individual layers are labeled with QD with different emission wavelengths. ${ }^{[25]}$

Sidewall electrodes: the mean fluorescence intensity was extracted using ImageJ. The result shown in Figure S4c showed that the mean intensity was in the same range ( $\sim 5-55 \pm 5$ a.u.). In the sidewall configuration, profilometer measurement of hydrogel thickness was not possible, and therefore standard light microscopy was used. For each layer, a measurement ruler was placed to estimate the width of the layer, the results are presented in Figure S4c. 

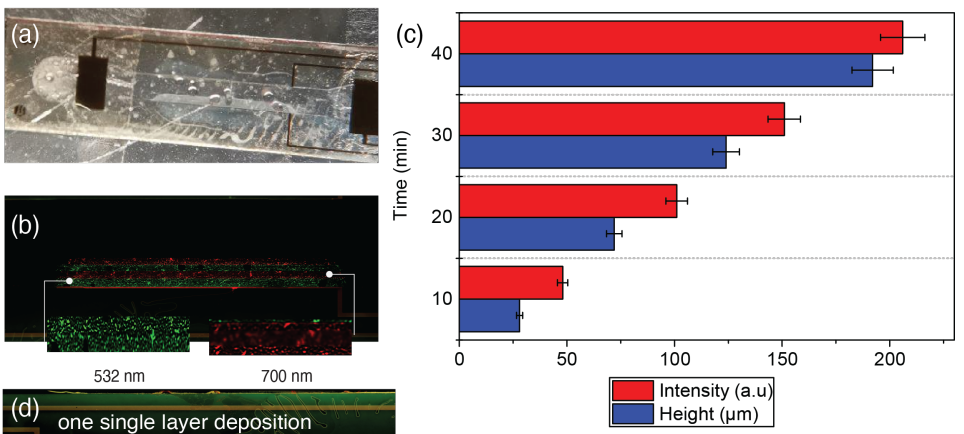

Figure S4: Image from (a) optical microscopy; (b) unfiltered fluorescence microscopy and (c) Mean profile height and fluorescence intensity charts versus time deposition as measured by optical microscopy and fluorescence microscopy for a four-step sequential electrodeposition of chitosan over 40 minutes total deposition time. A total of four hydrogel layers of QD-labelled chitosan $\left(\left(\lambda_{\text {emission }}=532 \mathrm{~nm}\right.\right.$; and $\left.700 \mathrm{~nm}\right)$ were assembled

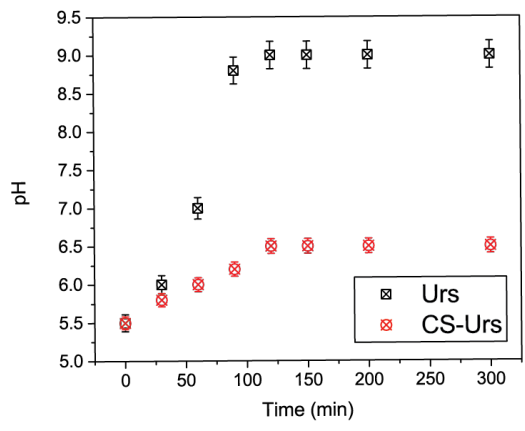

(a)

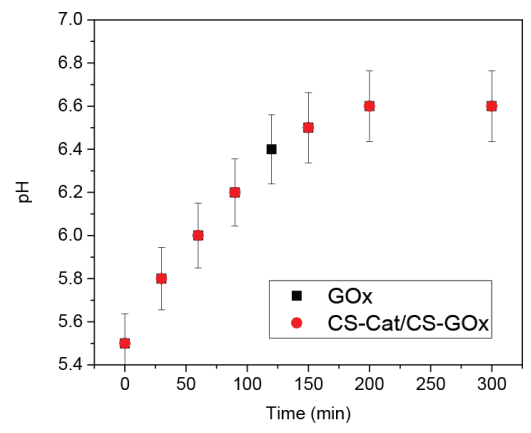

(b)

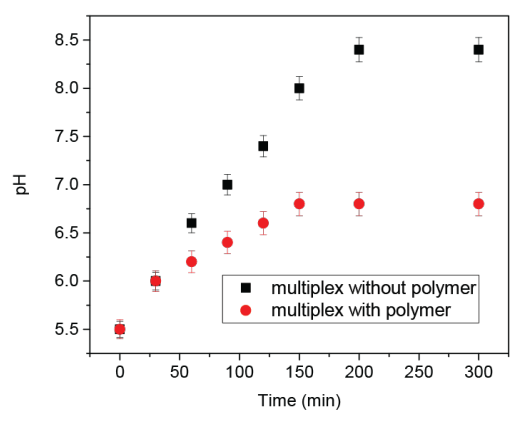

(c)

Figure S5: pH for (a) Urs and CS-Urs; (b) GOx and CS-GOx and (c) multiplex with and without polymer. Reactions were performed in NaAc buffer, $\mathrm{pH}$ 5.5. 


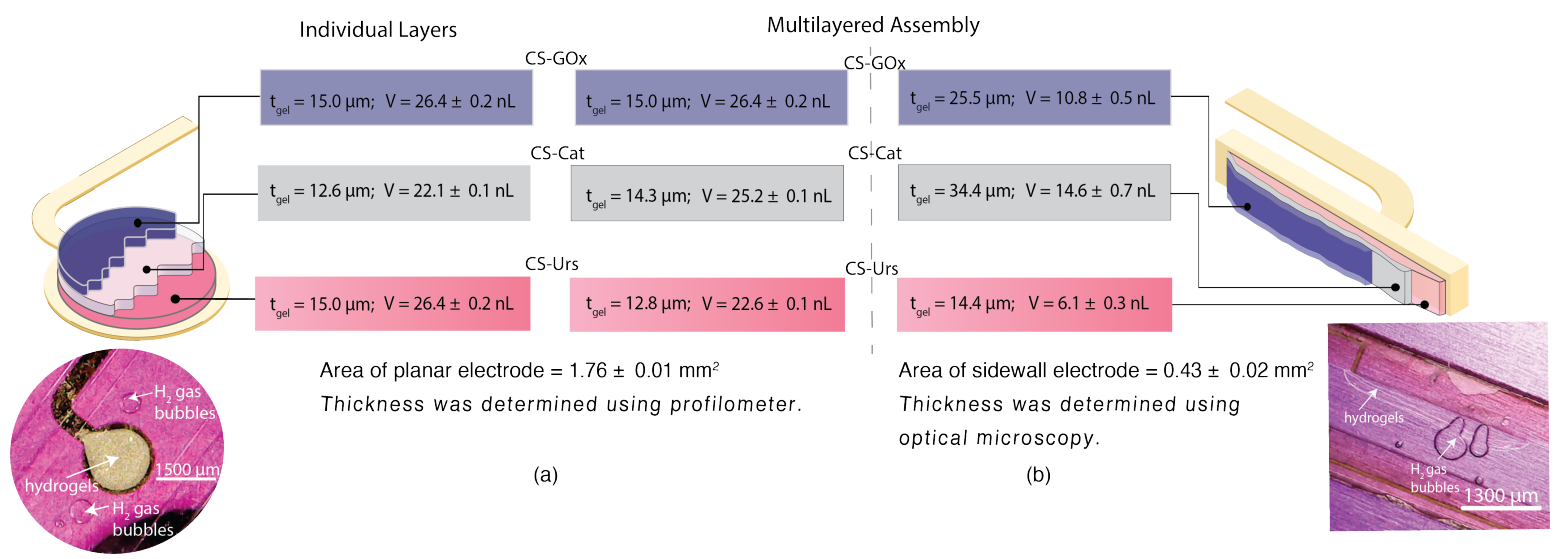

Figure S6: Schematic of the hydrogel layers for individual enzyme deposition and multiplex deposition conditions using (a) planar electrode geometry and (b) sidewall electrode geometry.

\section{$2.2 \mathrm{pH}$ measurement during catalysis}

\subsection{Calculation of hydrogel volume}

Figure S6 shows the estimated volume of each hydrogel layer for the two electrode configurations; (a) planar electrode and (b) sidewall electrode. For the planar electrode (Figure S6a), thickness was determined for both the Multilayerd Assembly and Individual Layer configurations. The thickness of the hydrogel $\left(t_{g e l}\right)$ was determined using the profile measurement method, performed by removing the upper glass of the channel. The values of $t_{g e l}$ are the thicknesses of the individual hydrogel layers (i.e. not the cumulative thickness).

For the sidewall electrode (Figure S6b), the thickness of the hydrogel layers was estimated by light microscopy. The thickness was measured after preparing the multilayered CS-Urs / CS-Cat / CS-GOx hydrogel assembly, using the same current density and deposition time as in the planar electrode case. The values of $t_{g e l}$ are the thicknesses of the individual hydrogel layers (i.e. not the cumulative thickness).

\subsection{Calculation of enzyme active fraction}

\section{Theoretical unit Urs in solution}

$$
U_{\text {Urs, theoretical }}=\frac{200 \text { unit }}{1 \mathrm{~mL}} \times \text { volume of microfluidic channel }
$$

\section{Active unit Urs based on $V_{\max }$}

One mole of urea produces two moles of ammonia. The extracted $V_{\max }$ of the reaction gives $\mathrm{M}_{\text {urea }} / \mathrm{min}$, which corresponds to $\mathrm{M}_{\mathrm{NH}_{3}} / \mathrm{min} \times 0.5$. Then the active unit can be estimated by multiplication with the microfluidic channel volume of the reaction $(3.5 \mu \mathrm{L}$ for the planar electrode and $2.5 \mu \mathrm{L}$ for the narrow channel sidewall electrode).

$$
U_{\text {Urs, active }}=\left(V_{\max } \times 2\right) \frac{M_{\mathrm{NH}_{3}}}{\min } \times \text { Volume of reaction }
$$




\section{Active unit GOx based on $V_{\max }$}

One mole of glucose produces one mole of gluconic acid. $V_{\max }$ of the reaction yields $M_{\text {gluconic acid }} / \mathrm{min}$, which corresponds to a of one mole of $M_{\text {gluconic acid }} / \mathrm{min}$. Therefore it is directly calculable to estimate the active unit by multiplying the reaction volume.

Theoretical unit CS-enzymes in hydrogel

$$
U_{\text {theoretical }}=\frac{\text { initial theoretical units in channel } \times \text { coupling efficiency }}{\text { volume of hydrogel }}
$$

Active units of CS-enzymes in hydrogel gel based on $V_{\max }$

$$
\begin{gathered}
U_{\mathrm{CS}-\text { Urs, active }}=\left(V_{\max } \times 2\right) \frac{M_{\mathrm{NH}_{3}}}{\min } \times \text { Volume of hydrogel } \\
U_{\text {CS-GOx, active }}=\left(V_{\max }\right) \frac{M_{\text {gluconicacid }}}{\min } \times \text { Volume of hydrogel }
\end{gathered}
$$

Fraction of active units

$$
\frac{\text { active unit }}{\text { initial unit }} \times 100 \%
$$

\subsection{Reproducibility}




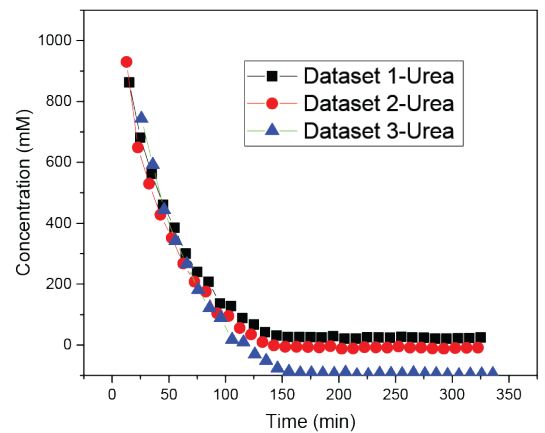

i

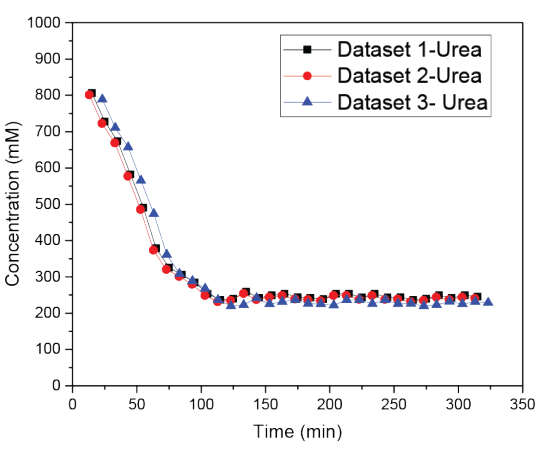

i

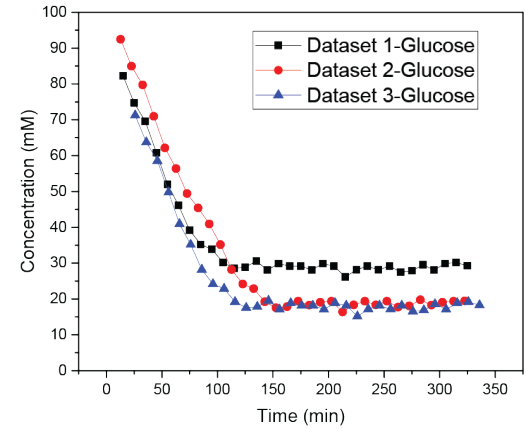

ii

(a)

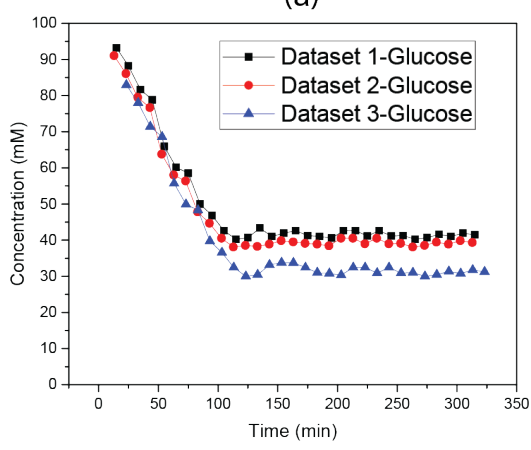

ii

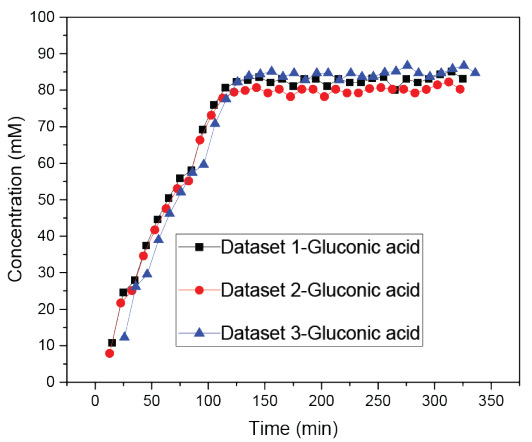

iii

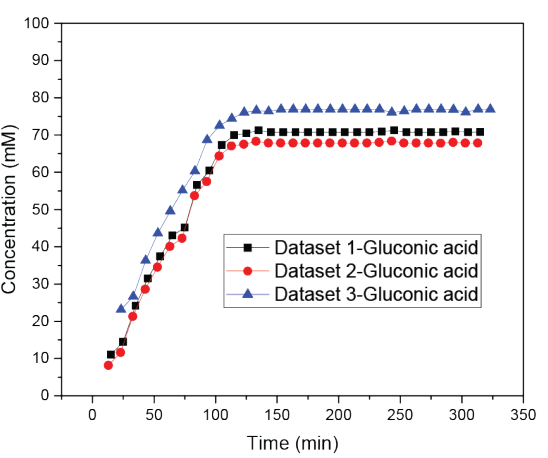

iii

(b)

Figure S7: Experiment reproducibility. Extracted concentration results from ${ }^{1} \mathrm{H}$ NMR spectra of the multi-layered hydrogel assembly CS-Urs / CS-Cat / CS-GOx exposed to a solution of $100 \mathrm{mM}$ glucose, $1000 \mathrm{mM}$ urea and $50 \mathrm{mM}$ TSP. The experiment was performed 3 times using the planar (a) and sidewall (b) electrode configurations. Plotted are the urea (i), glucose (ii), and gluconic acid (iii) concentrations as a function of time. 


\subsection{Solution experiments using Helmholtz microcoil}
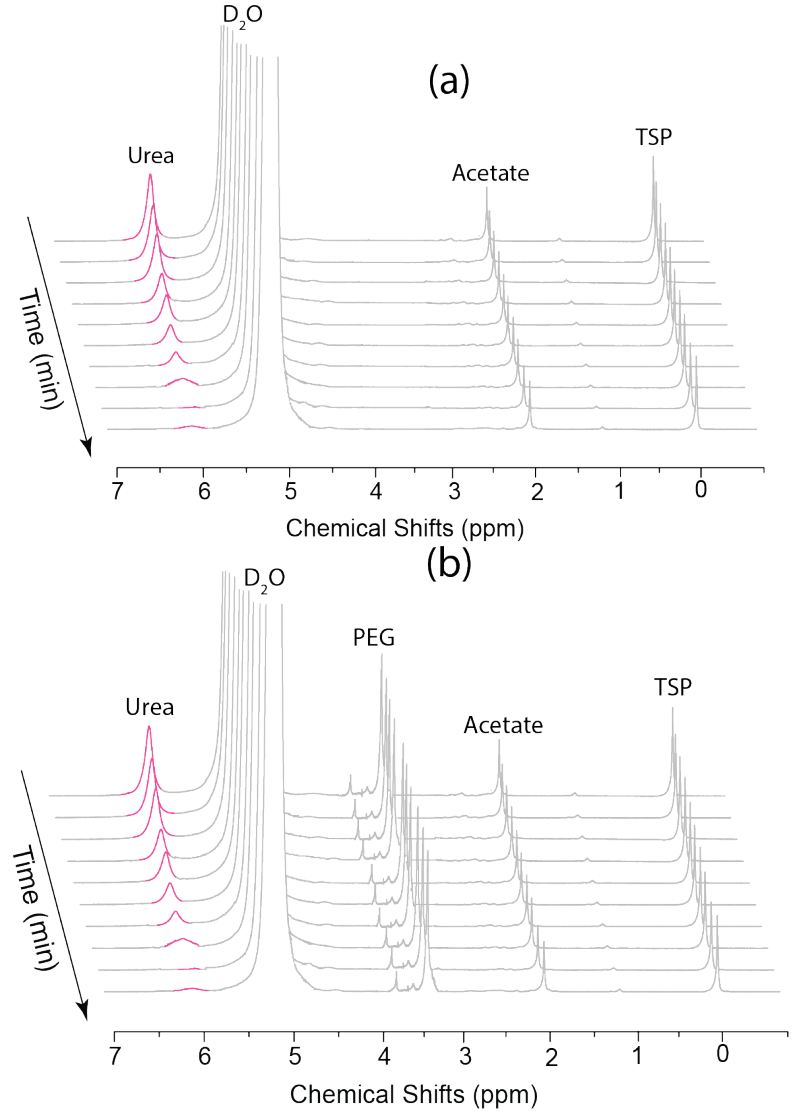

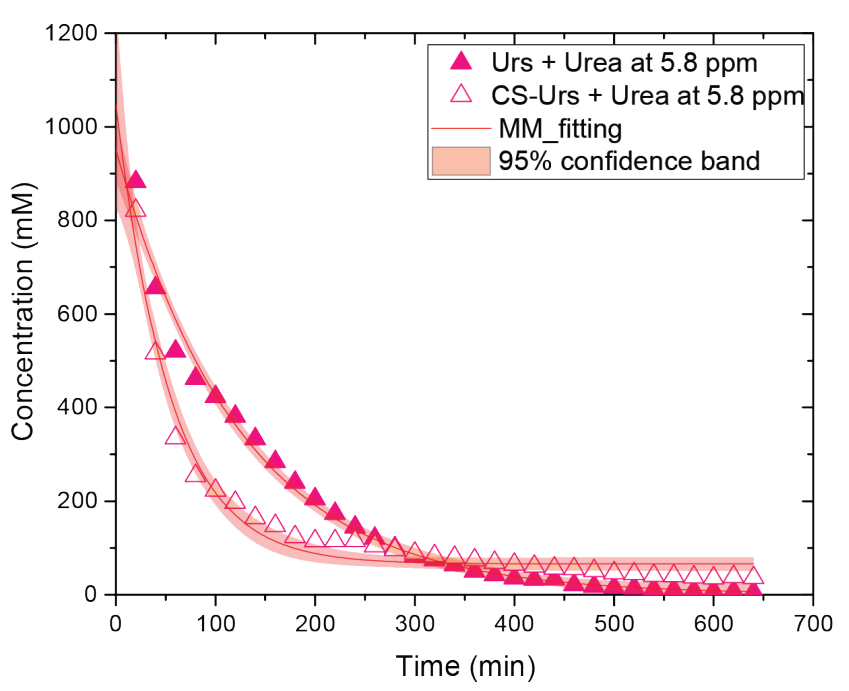

(c)

Figure S8: Urease and CS-Urs solution experiments. ${ }^{1} \mathrm{H}$ NMR spectra of (a) Urs; (b) CS-Urs, each with $1000 \mathrm{mM}$ of urea in solution with $50 \mathrm{mM}$ of TSP as a reference and (c) extracted urea concentrations from the NMR results in (a) and (b). Closed symbols: Urs in solution, open symbols: CS-Urs in solution. All solutions were prepared in $200 \mathrm{mM}$ $\mathrm{NaAc}, \mathrm{pH}$ 5.5. 


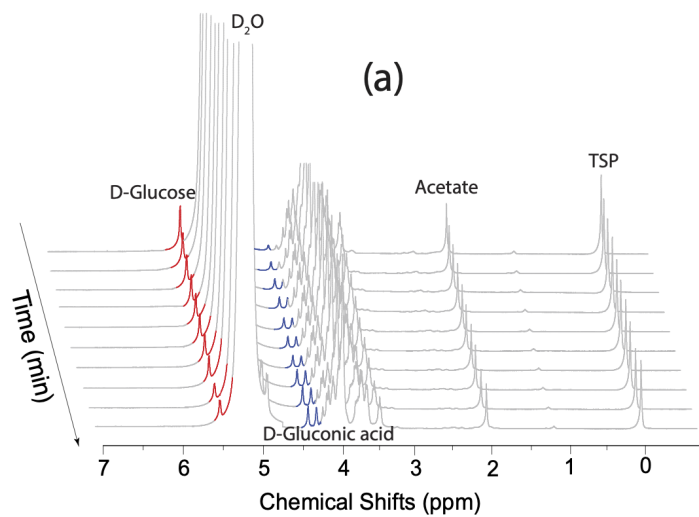

(b)

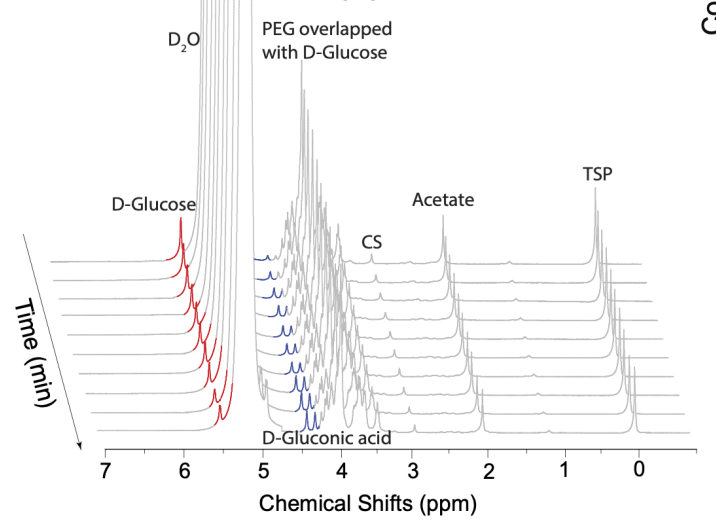

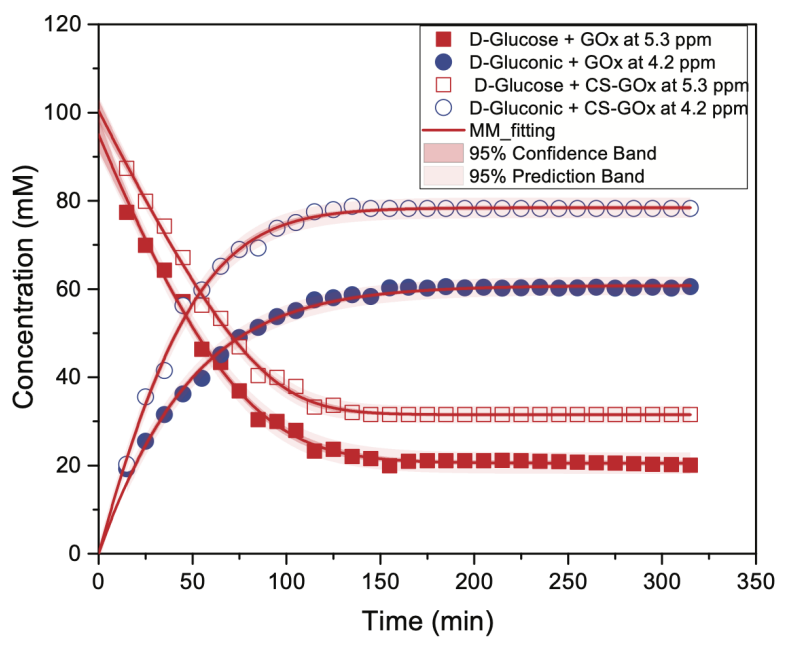

(c)

Figure S9: Glucose oxidase and CS-GOx solution experiments. ${ }^{1} \mathrm{H}$ NMR spectra of (a) GOx; (b) CS-GOx, each with $100 \mathrm{mM}$ glucose in solution with $50 \mathrm{mM}$ of TSP as a reference and (c) extracted concentrations from the NMR results in (a) and (b). Closed symbols: GOx in solution, open symbols: CS-GOx in solution. All solutions were prepared in 200 mM NaAc, pH 5.5. 


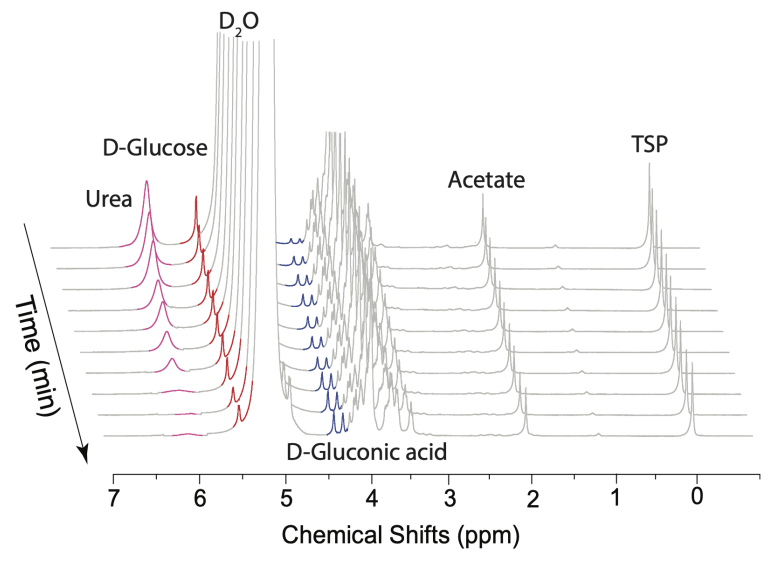

(a)

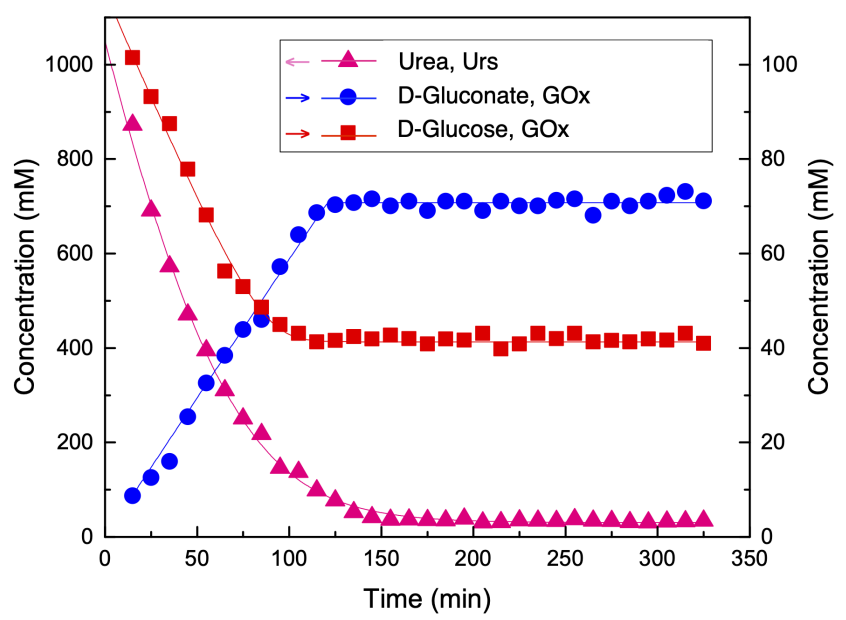

(b)

Figure S10: Urs, GOx, and Cat in solution. ${ }^{1} \mathrm{H}$ NMR spectra of the enzyme mixture in solution with $100 \mathrm{mM}$ of glucose, $1000 \mathrm{mM}$ urea and $50 \mathrm{mM}$ of TSP as a reference and (b) extracted reagent and product concentrations from the NMR results in (a). Left axis: urea concentration; Right axis: glucose and gluconic acid concentration. All solutions were prepared in $200 \mathrm{mM} \mathrm{NaAc}$, pH 5.5. 


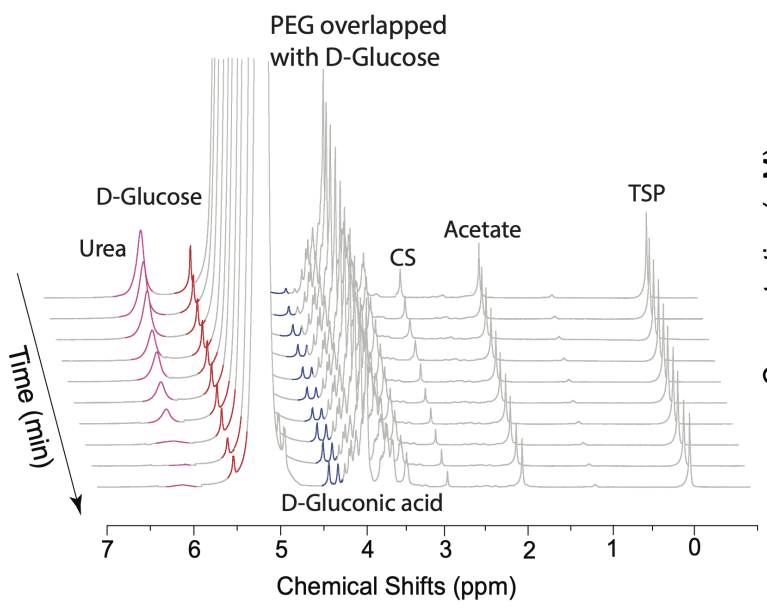

(a)

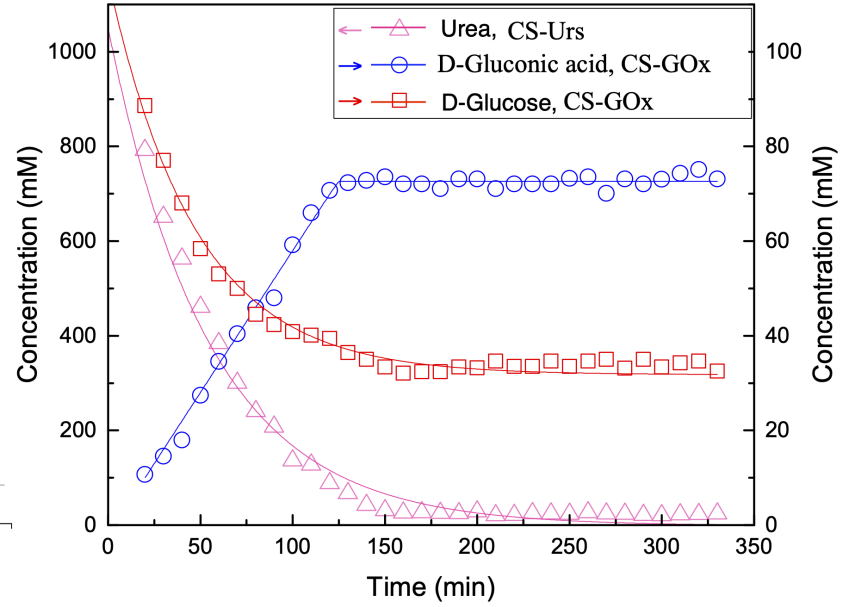

(b)

Figure S11: CS-Urs, CS-GOx, and CS-Cat in solution. ${ }^{1} \mathrm{H}$ NMR spectra of the CS-enzyme mixture with $100 \mathrm{mM}$ of glucose, $1000 \mathrm{mM}$ urea and $50 \mathrm{mM}$ of TSP as a reference and (b) extracted reagent and product concentrations from the NMR results in (a). Left axis: urea concentration; Right axis: glucose and gluconic acid concentration. All solutions were prepared in $200 \mathrm{mM} \mathrm{NaAc}, \mathrm{pH}$ 5.5. 


\section{References}

[29] H. Davoodi, N. Nordin, L. Bordonali, J. G. Korvink, N. MacKinnon, V. Badilita, Lab on a Chip 2020, 20, $3202-3212$.

[2] M. Focke, D. Kosse, C. Müller, H. Reinecke, R. Zengerle, F. von Stetten, Lab on a Chip 2010, 10, 1365-1386.

[25] N. Nordin, L. Bordonali, V. Badilita, N. MacKinnon, Macromolecular bioscience 2019, 19, 1800372.

[4] Y. Liu, B. Zhang, K. M. Gray, Y. Cheng, E. Kim, G. W. Rubloff, W. E. Bentley, Q. Wang, G. F. Payne, Soft Matter 2013, 9, 2703-2710.

[5] N. Spengler, J. Höfflin, A. Moazenzadeh, D. Mager, N. MacKinnon, V. Badilita, U. Wallrabe, J. G. Korvink, PloS one 2016, 11, e0146384. 